\title{
Characterization of Swirl-Venturi Lean Direct Injection Designs for Aviation Gas-Turbine Combustion
}

\author{
Christopher M. Heath ${ }^{*}$ \\ NASA Glenn Research Center, Cleveland, OH, 44135
}

\begin{abstract}
Injector geometry, physical mixing, chemical processes, and engine cycle conditions together govern performance, operability and emission characteristics of aviation gasturbine combustion systems. The present investigation explores swirl-venturi lean direct injection combustor fundamentals, characterizing the influence of key geometric injector parameters on reacting flow physics and emission production trends. In this computational study, a design space exploration was performed using a parameterized swirl-venturi lean direct injector model. From the parametric geometry, 20 three-element lean direct injection combustor sectors were produced and simulated using steady-state, Reynolds-averaged Navier-Stokes reacting computations. Species concentrations were solved directly using a reduced 18-step reaction mechanism for Jet-A. Turbulence closure was obtained using a nonlinear $\kappa-\varepsilon$ model. Results demonstrate sensitivities of the geometric perturbations on axially averaged flow field responses. Output variables include axial velocity, turbulent kinetic energy, static temperature, fuel patternation and minor species mass fractions. Significant trends have been reduced to surrogate model approximations, intended to guide future injector design trade studies and advance aviation gas-turbine combustion research.
\end{abstract}

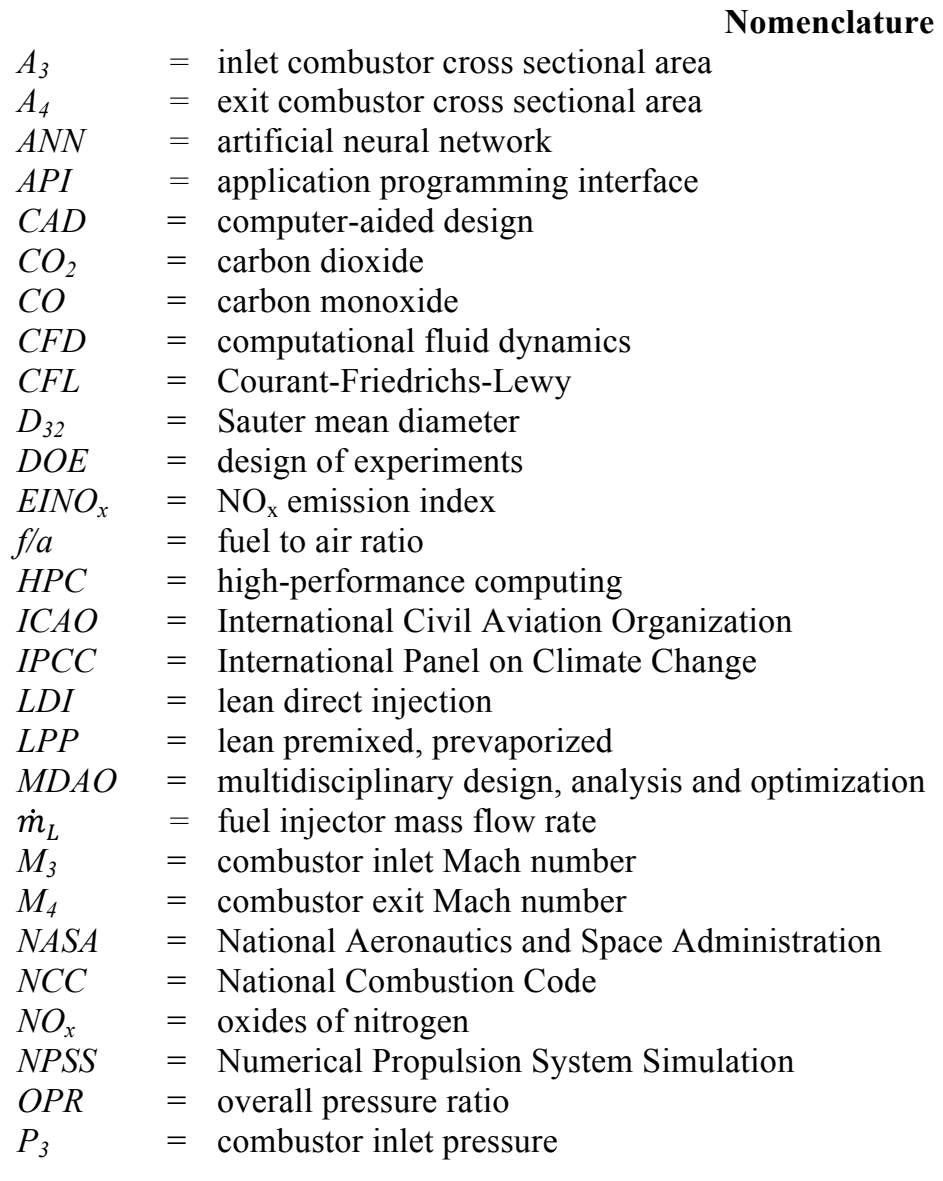

* Aerospace Engineer, Multidisciplinary Design, Analysis and Optimization Branch, MS 5-10, Non-member 


$\begin{array}{ll}P a S R & =\text { partially-stirred reactor } \\ P F R & =\text { plug flow reactor } \\ P S R & =\text { perfectly-stirred reactor } \\ R A N S & =\text { Reynolds-averaged Navier-Stokes } \\ R S E & =\text { response surface equation } \\ R S T M & =\text { Reynolds stress turbulence model } \\ T_{F u e l} & =\text { fuel temperature } \\ T K E & =\text { turbulent kinetic energy } \\ T_{3} & =\text { combustor inlet static temperature } \\ T_{4} & =\text { combustor exit static temperature } \\ U H C & =\text { unburned hydrocarbon } \\ U_{S} & =\text { unmixedness parameter } \\ U & =\text { flame non-uniformity parameter } \\ V B A & =\text { Visual Basic for Applications } \\ V_{3} & =\text { combustor inlet velocity } \\ W_{3} & =\text { combustor inlet mass flow rate } \\ W_{4} & =\text { combustor exit mass flow rate } \\ X_{1} & =\text { fuel injector module diameter } \\ X_{2} & =\text { helical-axial vane angle } \\ X_{3} & =\text { venturi half angle } \\ X_{4} & =\text { number of injector vanes } \\ \Delta P & =\text { combustor air flow pressure drop } \\ \Delta P_{\mathrm{L}} & =\text { injector fuel flow pressure drop } \\ \Delta T_{\mathrm{profile}} & =\text { combustor temperature profile factor } \\ \eta_{c} & =\text { combustion efficiency } \\ \sigma & =\text { fuel surface tension } \\ \mu_{L} & =\text { fuel dynamic viscosity } \\ \rho_{A} & =\text { injector air density } \\ & \end{array}$

\section{Introduction}

$\mathrm{T}$ he International Panel on Climate Change (IPCC) estimates civil aviation accounts for 2-3 percent of the anthropogenic-induced radiative forcing effect and carbon dioxide $\left(\mathrm{CO}_{2}\right)$ emissions global-wide. Both contributions are forecast to double by the year 2050. In addition to $\mathrm{CO}_{2}$, oxides of nitrogen $\left(\mathrm{NO}_{\mathrm{x}}\right)$ are expected to increase in-line with the year-over-year projected expansion of the commercial airline industry. ${ }^{1}$ Policy options to further regulate aviation emissions are under current international scrutiny. To aid industry in meeting impending mandates and combat the global emissions inventory, NASA aims to advance state-of-the-art research technologies that will aggressively reduce aircraft fuel consumption, landing take-off emissions and high altitude cruise $\mathrm{NO}_{\mathrm{x}}$ up to $75 \%$ by the 2020 time frame.

The lean direct injection (LDI) combustor is one engine technology that continues to show promise toward satisfying NASA fuel and emission reduction targets. Previous LDI combustion experiments have reported reduced fuel burn and $\mathrm{NO}_{\mathrm{x}}$ emissions, relative to the 1996 International Civil Aviation Organization (ICAO) standard, with no discernable impact to carbon monoxide (CO) or unburned hydrocarbon (UHC) production rates. ${ }^{2,3}$ The purpose of this investigation is to characterize the sensitivity of geometric LDI design changes on combustor flow physics and emission trends.

To date, no prior studies have fully characterized geometric impacts on reacting LDI combustor performance and emission production. Independent experimental investigations have examined the isolated effects of injector module size, confinement ratio, air swirler vane angle, swirler interaction (co-rotating and counter-rotating), swirler type (radial or axial), and fuel nozzle location. ${ }^{2,4,5,6}$ Computational efforts have also analyzed the effect of air swirler vane angle $\left(45^{\circ}\right.$ and $\left.60^{\circ}\right)$ on non-reacting and reacting multi-point LDI combustor arrays. ${ }^{7}$ Still, the majority of former research has been limited to non-reacting flows, failing to link injector geometry with the fuel-air mixing process and combusting environment.

Historically, combustor design has been performed using semi-empirical models supported by experimental data. ${ }^{8,9}$ Incorporating high-fidelity simulation has been considered unaffordable given the computational resolution and expense required to resolve multi-phase reacting flow fields. Recent surrogate model approaches along with efficiency gains in modern-day high performance computing (HPC) have enabled high-fidelity simulations to begin 
playing a more pivotal role in early gas-turbine combustor development. For example, combustor design optimization through adaptive sampling techniques leveraging Kriging and co-Kriging models have been recently demonstrated at the conceptual design level. ${ }^{10,11}$ While these efforts have not addressed LDI combustors specifically, they have made significant strides in applying surrogate modeling techniques to accelerate the high-fidelity combustor design process.

Toward advancing the surrogate modeling approach, this study applies multi-fidelity analysis methods to characterize four geometric design parameters of multi-point swirl-venturi LDI combustion. As displayed in Fig. 1, the motivation is to define a quantitative link between fuel injector geometry, flow field aerodynamics, engine cycle conditions, and reactive chemistry. Through this investigation, significant trends have been reduced to surrogate model approximations suitable for predicting general system-level trends at the conceptual design stage. Better understanding of important design tradeoffs will help guide the policy-making effort and assist engineers in maturing next-generation fuel injection systems for aviation.

\section{Background}

Current best practices for low-order emissions prediction include correlations from flame tube experiments and reactor network models based on chemical kinetics. Although much research has been devoted to reactor networks developed using combinations of partially-stirred reactors (PaSR), perfectly-stirred reactors (PSR), and plug flow reactors (PFR), ${ }^{12,13}$ the models remain non-general, difficult to modify, and lack geometric information necessary for combustor design. Not to mention, considerable effort and experience is required to calibrate reactor networks from experimental and computational datasets. Similar drawbacks exist for empirically driven emission correlations that remain combustor specific and capture $\mathrm{NO}_{\mathrm{x}}$ exclusively as a function of upstream combustor temperature, pressure and fuel-to-air ratio. The link between injector geometry and flow physics, cycle conditions and chemistry is largely neglected in both cases. At best, injector geometry-based emission contributions are subsumed within batch reactor model properties or coefficient terms related to physical mixing rates.

Taking an alternate approach to low-order emissions modeling, this research places specific emphasis on injector geometry and physical mixing as critical aspects for predicting combustor performance. It is well known that fuel injector geometry largely governs the fuel-air mixing process and production of minor species. Inefficient mixing produces fuel-rich, high temperature zones that promote $\mathrm{NO}_{\mathrm{x}}$ formation via the thermal $\mathrm{NO}_{\mathrm{x}}$ pathway. In contrast, overly efficient mixing leads to high turbulence, flame instability, greater combustor pressure loss, and reduced core engine efficiency. This work is a first step toward improving understanding of such trades and defines several relationships between swirl-venturi LDI geometry, combustor performance, and emission characteristics.

\section{Lean Direct Injection Combustion}

Lean direct injection combustion was developed as an extension of lean-premixed-prevaporized (LPP) combustion. Both strategies reduce $\mathrm{NO}_{\mathrm{x}}$ by operating at equivalence ratios near the lean blowout limit. Given the known susceptibility of LPP systems to autoignition and flashback ${ }^{14}$, LDI strategies were introduced as lowemission alternatives suitable for both aviation and ground-based applications. In LDI, all combustion air (except that used for liner cooling) is introduced into the combustion chamber through the dome. ${ }^{2,6}$ Non-premixed, atomized fuel is injected directly into the flame zone, where combustion occurs near the lower flammability limit. ${ }^{14}$

Multi-point LDI combustors consist of many integrated fuel injector modules which force localized turbulent micro-scale mixing and assist in the fuel breakup process. Rapid fuel vaporization and mixing are crucial for producing a homogeneous reactant mixture and uniform temperature distribution throughout the combustion chamber. Quick fuel vaporization also enables combustor length to be reduced, saving on core engine weight.

For multi-point swirl-venturi LDI, each injector module is a three-part assembly, comprised of a helical-axial vane set, convergent-divergent venturi, and pressure-swirl nozzle, which atomizes and injects liquid fuel near the venturi throat. (See Fig. 2a). During operation, each injector module produces a toroidal recirculating flow, which 
forms an aerodynamically stabilized flame anchor site just downstream of the fuel injector tip. First generation LDI combustor concepts contained multiple fuel stages to support a broad operability range, but were discovered to still suffer poor performance near idle conditions. To combat this limitation, recent strategies have been introduced where a LDI pilot stage is incorporated and activated to help stabilize low power operation. Additional stages are subsequently engaged for mid to high power settings. Figure $2 \mathrm{~b}$ contains a conceptual 5 -stage LDI combustor sector, including a recessed pilot stage.

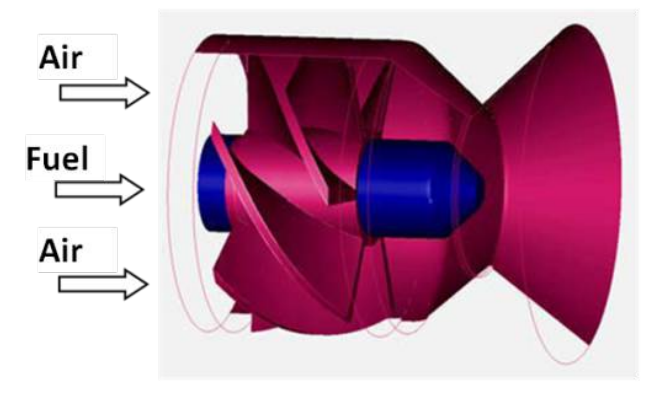

Figure 2a. Full-section view of single LDI module.

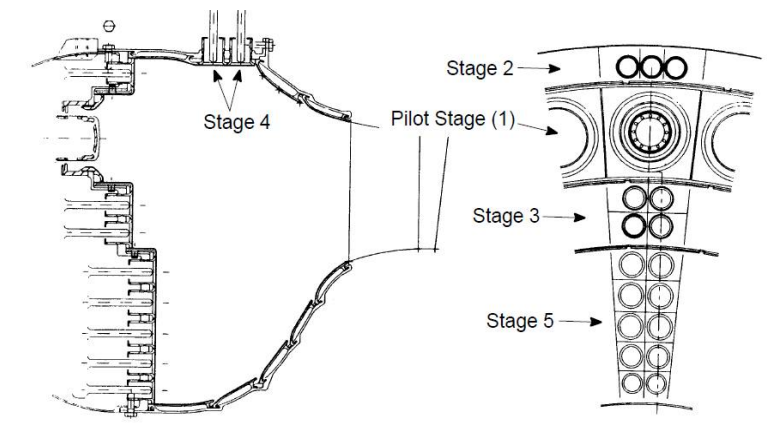

Figure 2b. 5-Stage LDI combustor sector concept.

\section{A. Parametric Geometry Definition}

IV. Problem Formulation

To study swirl-venturi LDI fundamentals, a parametric modeling scheme was applied to produce a notional, $15^{\circ}$ three-element LDI combustor sector. (See Fig. 3). The computational domain resembles a subsection of the $5^{\text {th }}$ stage in Fig. 2b. For simplicity, liner cooling and turbine entrance effects were omitted from this study. The combustor passageway was modeled as a sector of a straight flow-through circular duct. The combustor computational length (measured from the dome to the downstream exit plane) was maintained for all combustor designs at $24.13-\mathrm{cm}$ (9.5in). The LDI modules contained in each combustor sector were designed using four parameters, denoted $\mathrm{X}_{1}$ through $\mathrm{X}_{4}$. Identical parameter values were assigned to all three LDI modules of any given sector. Basic parameter descriptions and ranges are listed in Table 1.

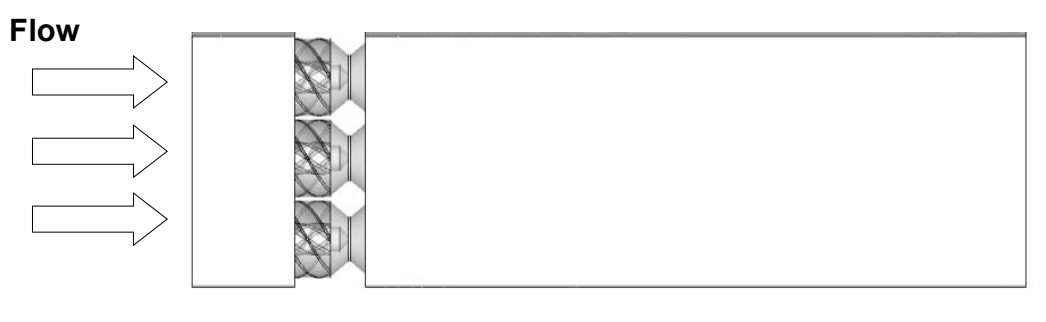

Figure 3. Geometric definition of LDI combustor sector flow domain.

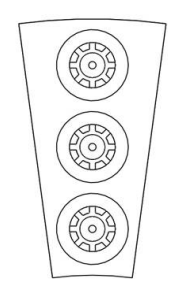

\begin{tabular}{clc}
\hline \multicolumn{3}{c}{ TABLE 1: Design Variables and Ranges } \\
\hline Design Variable & \multicolumn{1}{c}{ Description } & Range \\
\hline $\mathrm{X}_{1}$ & LDI Module Diameter (cm) & $1.810 \leq \mathrm{X}_{1} \leq 3.016$ \\
$\mathrm{X}_{2}$ & Vane Angle (deg) & $35.0 \leq \mathrm{X}_{2} \leq 85.0$ \\
$\mathrm{X}_{3}$ & Venturi Angle (deg) & $25.0 \leq \mathrm{X}_{3} \leq 55.0$ \\
$\mathrm{X}_{4}$ & Number of Vanes & $4 \leq \mathrm{X}_{4} \leq 8$ \\
\hline
\end{tabular}

Design variable $\mathrm{X}_{1}$ represents fuel injector module diameter, which defines the size of all three injector modules within a given sector design. $X_{1}$ also affects fuel injector packing efficiency, as a smaller module diameter reduces the spacing between adjacent injectors. This coupling is demonstrated in Fig. 4, where the sector on the right contains smaller diameter injector modules placed in closer proximity. To further simplify the parameterization scheme, the inner combustor radius of each sector design was set to 8.5 times the value of $X_{1}$. Similarly, the outer sector radius was scaled to accommodate three evenly spaced injector modules within each combustor cross-section. 


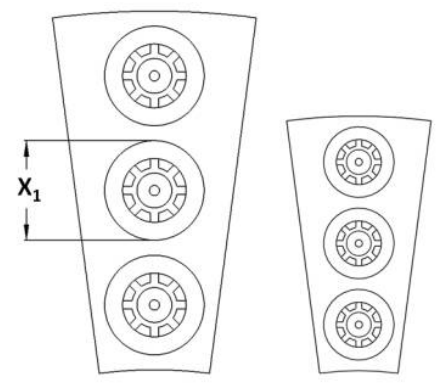

Figure 4. Example scaling of injector spacing with LDI module diameter.

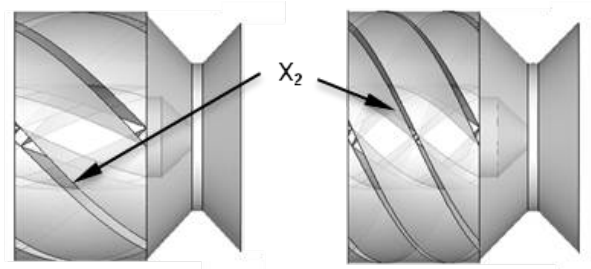

Figure 5a: Effect of increasing swirler vane angle.
The sector angle was fixed across the entire design space to $15^{\circ}$. The physical geometric scaling with $X_{1}$ ensured an identical confinement ratio and injector air velocity for all designs. This helped match the momentum ratio of the gas to liquid phase streams by permitting mass flow to vary proportionally between configurations.

$\mathrm{X}_{2}$ represents the angle of the helical-axial-swirler blades. The effect of increasing $\mathrm{X}_{2}$ while holding all other design parameters fixed is demonstrated in Fig. 5a. A formal definition of helical vane angle as applied to axialbladed LDI hardware is given in Ref. 4.

$\mathrm{X}_{3}$ controls the equivalent converging and diverging half angles of the venturi. Venturi angles were measured relative to the horizontal, as indicated by Fig. $5 \mathrm{~b}$.

$\mathrm{X}_{4}$ was modeled as a discrete variable corresponding to the number of helical vanes contained in each injector module air passage. $\mathrm{X}_{4}$ was restricted to integer values between 4 and 8 , inclusive.

Given $\mathrm{X}_{1}$ through $\mathrm{X}_{4}$, Table 2 lists the complete set of injector parameter combinations that comprise the 20 combustor sectors analyzed in this study. The set corresponds to a modified optimal Latin hypercube DOE sampling with $\mathrm{X}_{4}$ modified to be discrete.

TABLE 2: Optimal Latin Hypercube Design Matrix

\begin{tabular}{ccccc}
\hline Design \# & $\mathrm{X}_{1}(\mathrm{~cm})$ & $\mathrm{X}_{2}(\mathrm{deg})$ & $\mathrm{X}_{3}(\mathrm{deg})$ & $\mathrm{X}_{4}$ \\
\hline 1 & 2.318 & 40.37 & 49.75 & 6 \\
2 & 2.635 & 70.39 & 42.25 & 6 \\
3 & 2.508 & 44.99 & 33.25 & 7 \\
4 & 2.572 & 56.54 & 36.25 & 4 \\
5 & 2.191 & 63.46 & 37.25 & 7 \\
6 & 2.127 & 61.15 & 28.75 & 4 \\
7 & 2.064 & 65.77 & 34.75 & 5 \\
8 & 2.381 & 51.91 & 43.75 & 5 \\
9 & 2.000 & 58.84 & 45.25 & 5 \\
10 & 1.810 & 47.30 & 25.75 & 7 \\
11 & 2.254 & 79.63 & 48.25 & 6 \\
12 & 3.016 & 42.68 & 46.75 & 6 \\
13 & 2.826 & 38.06 & 30.25 & 8 \\
14 & 2.889 & 49.61 & 51.25 & 8 \\
15 & 2.445 & 81.94 & 52.75 & 8 \\
16 & 2.762 & 77.32 & 54.25 & 5 \\
17 & 1.937 & 72.70 & 39.25 & 4 \\
18 & 2.699 & 68.08 & 31.75 & 8 \\
19 & 1.873 & 54.23 & 40.75 & 7 \\
20 & 2.953 & 75.01 & 27.25 & 4 \\
\hline
\end{tabular}




\section{B. Operational Constraints}

To ensure valid comparison between sector designs, the upstream combustor static pressure $\left(\mathrm{P}_{3}\right)$, static temperature $\left(\mathrm{T}_{3}\right)$, and axial airflow velocity $\left(\mathrm{V}_{3}\right)$ were held constant for all simulations. Table 3 lists the upstream conditions, considered representative of a next-generation, high overall pressure ratio (OPR) engine operating near $100 \%$ power. To force $\mathrm{P}_{3}$ to be consistent across the design space, the downstream pressure, $\mathrm{P}_{4}$, was varied between combustor configurations to account for individual pressure losses. The combustor exit temperature $\left(\mathrm{T}_{4}\right)$ was also fixed between designs to $1735.5-\mathrm{K}$. The required $\mathrm{f} / \mathrm{a}$ to achieve this target $\mathrm{T}_{4}$ was estimated using an adiabatic flame temperature calculation, assuming $99.5 \%$ combustion efficiency.

\begin{tabular}{lc}
\hline \multicolumn{2}{c}{ Table 3: Combustor Operating Conditions } \\
\hline $\mathrm{T}_{3}(\mathrm{~K})$ & 810.0 \\
$\mathrm{P}_{3}(\mathrm{MPa})$ & 2.757 \\
$\mathrm{~V}_{3}(\mathrm{~m} / \mathrm{s})$ & 12.2 \\
$\mathrm{~T}_{4}(\mathrm{~K})$ (target) & 1735.5 \\
$\mathrm{f} / \mathrm{a}$ & 0.0279 \\
\hline
\end{tabular}

\section{Performance and Emission Metrics}

The following metrics were used to evaluate the performance of each LDI sector configuration, and considered primary objective functions.

1. Overall static pressure drop $(\Delta \mathrm{P})$ across the combustor

2. Combustor length determined by temperature profile factor

3. Flame non-uniformity measured 5-mm axially from the dome plane

4. Predicted $\mathrm{EINO}_{\mathrm{x}}$ at the downstream combustor exit plane

Approximate combustor lengths were calculated by measuring the axial distance from the dome at which the temperature profile factor fell below a threshold of 0.1. Profile factor was given by Eq. (1) and adopted from Ref. 15 , where $T_{m r}$ is the maximum circumferentially averaged temperature for all radii of a given sector.

$$
\Delta T_{\text {profile }}=\frac{T_{m r}-T_{4}}{T_{4}-T_{3}}
$$

Analogous to profile factor is the flame non-uniformity parameter, which is presented here for the first time. The non-uniformity metric provides a means to compare flame structure and identify flame irregularities across multiple injector elements of a given sector design. Flame non-uniformity is calculated by taking the local variance between temperature distributions for a set of injector elements and dividing by the local average temperature distribution of those injectors within a single axial plane.

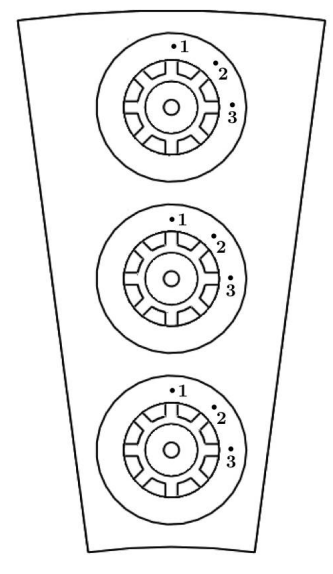

Figure 6. Flame non-uniformity metric definition.
For example, Fig. 6 identifies three geometrically identical discrete locations in space taken near each injector element of a given sector design, labeled 1,2 and 3. The points are selected to be located well within the primary flame front of each injector. Assume $n$ is the number of discrete points from which the flame non-uniformity metric will be calculated. In this case, $n=3$. Take $m$ as the total number of injector elements contained in a given sector $(m=3)$. The local average temperature, $\mu$, for discrete locations $i=1,2, \ldots, n$ over injector elements $j$ $=1,2, \ldots, m$ is given by Eq. (2). Similarly, the local temperature variance is calculated using Eq. (3). The variable $x$ in Eqs. (2) and (3) denotes the local flame temperature extracted from each computational solution.

$$
\begin{gathered}
\mu_{i}=\frac{1}{m} \sum_{j=1}^{m} x_{i j} \\
\operatorname{var}\left(x_{i}\right)=\frac{1}{m} \sum_{j=1}^{m}\left(x_{i j}-\mu_{i}\right)^{2}
\end{gathered}
$$


The flame non-uniformity parameter, $U(x)$, is then given from Eq. (4) by averaging the temperature variance at each point-wise location divided by the local average temperature across injectors. A non-uniformity value of zero corresponds to a highly regular flame structure. In contrast, a large non-uniformity value corresponds to flames with irregular structure, often containing large temperature gradients and asymmetrical characteristics.

$$
U(x)=\frac{1}{n} \sum_{i=1}^{n} \frac{\operatorname{var}\left(x_{i}\right)}{\mu_{i}}
$$

Because flame non-uniformity characterizes irregularities in flame structure, the measurement is only practical at locations that fall well within the flame zone. For this study, discrete points were selected 5-mm axially downstream of the injector dome and only within the flame region. Also, a statistically large sample of points (>>3) taken at various radial and circumferential locations from each injector center was used to improve measurement resolution. Flame non-uniformity proved particularly helpful for quantitatively differentiating between sector designs producing regular and irregular flames. Regular flames were also characterized as having greater stability, as a lower temperature variance was evident across the set of injectors comprising the multi-element sector.

\section{Computational Tools, Numerical Methods and Software Integration}

\section{A. Geometry Handling}

The parametric combustor geometry was developed using a commercial computer-aided design (CAD) package, with relations driving many free model dimensions. Design parameters were manipulated programmatically through a Python-wrapped Visual Basic for Applications (VBA) executable that made calls through the CAD application programming interface (API). The positive injector geometry was subtracted from a $15^{\circ}$ annular wedge to produce the computational flow domain. The result was exported in a CAD neutral file format.

\section{B. Mesh Generation}

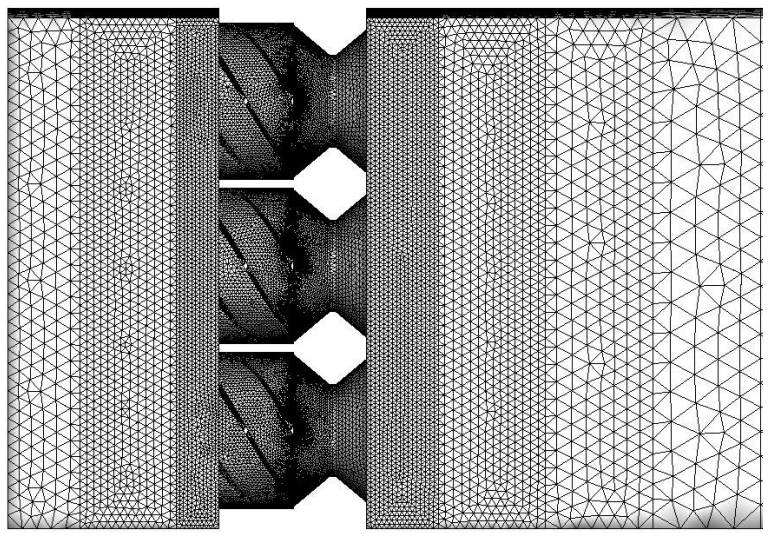

Figure 7. Sample unstructured tetrahedral surface grid near injector region.
A commercial meshing package was used to generate unstructured, tetrahedral volume grids for each of the sector designs defined in Table 2. Inside the mesh application, a scripted process was developed to enable automation. To ensure uniform grid quality control, the flow domain for each design was meshed using a multi-block approach. Each block was individually discretized with constraints placed on the maximum allowable gradient between cells and the maximum and minimum cell size. Each constraint was iteratively relaxed until all cells within each block met an aspect ratio criterion of 4.5 or less. All flow domains were meshed with roughly three million cells using geometry-based refinement near the injectors to capture boundary and shear-layer effects. Previous grid refinement studies for swirl-venturi LDI geometries have demonstrated one million tetrahedral cells per injector sufficiently resolves important features inside the vane passageways, including static pressure loss when compared to experimental results. ${ }^{16}$ Figure 7 displays a typical surface mesh near the injector region.

Periodic boundary conditions were applied on either angled side of each sector to simulate a full annular combustor. The upper and lower radial surfaces were assigned viscous adiabatic wall conditions, enabling wall and confinement effects to be simulated. A uniform velocity (normal to the upstream face) of $12.2 \mathrm{~m} / \mathrm{s} \mathrm{was} \mathrm{specified} \mathrm{at}$ the combustor inlet along with a turbulence intensity level of 5\%. Inlet mixing lengths were set equal to one-third of the flow domain height (which varied with $\mathrm{X}_{1}$ ). A farfield static pressure boundary condition was prescribed on each downstream exit surface. Figure 8 describes the boundary conditions applied to the control volume. All external surfaces not specified explicitly in the injector region, including the fuel nozzle, swirler blades and venturi, were treated as viscous adiabatic walls. 


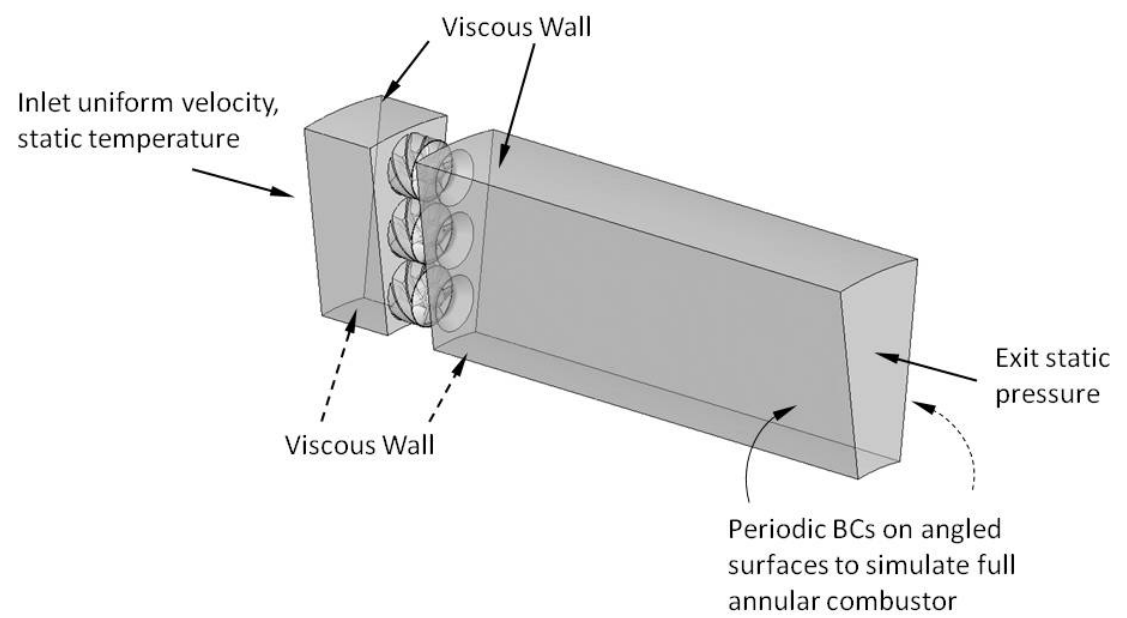

Figure 8. Boundary conditions applied to the computational domain.

\section{B. Low-Order Modeling}

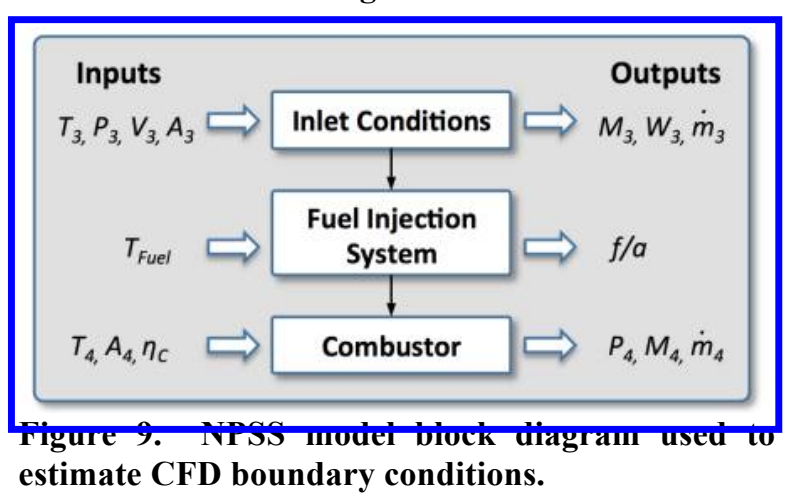

The Numerical Propulsion System Simulation (NPSS $)^{17}$ is a component-based zero-order cycle analysis code that has become the de-facto industry standard for steady-state engine simulation. With an object-oriented structure, NPSS contains a library of predefined components including inlets, diffusers, nozzles, combustors, ducts, compressors, and turbines, which may be linked to model many thermodynamic systems.

By combining several computational elements from the NPSS standard library, an isolated NPSS combustor model was developed. Model execution solved for steadystate mass flow rates and all undefined state variables at the entrance and exit of each NPSS flow element. Outputs were supplied as boundary conditions for initializing all CFD simulations. The NPSS model also calculated the f/a required to achieve the desired $\mathrm{T}_{4}$ of 1735.5-K. Figure 9 displays a diagram of the NPSS model, describing basic input and output parameters for each element. Within the model, the lower heating value for fuel was assumed 43.9$\mathrm{MJ} / \mathrm{kg}$, and the combustion efficiency, $\eta_{c}$, was set to $99.5 \%$. Cross sectional entrance and exit areas, $A_{3}$ and $A_{4}$, were computed directly from the geometry of each combustor configuration and specified as input to NPSS.

\section{High-Order Modeling}

The National Combustion Code (NCC) ${ }^{18,19}$ is a Navier-Stokes flow solver tailored for advanced chemistry and unsteady modeling of reacting liquid spray. NCC uses a cell-centered finite-volume spatial discretization for unstructured grids with pseudo-time preconditioning. A second-order accurate central-difference scheme is used for inviscid and viscous flux discretizations, with a Jameson operator (blend of $2^{\text {nd }}$ and $4^{\text {th }}$ order dissipation terms) applied for numerical stability. ${ }^{16}$ An explicit four-stage Runge-Kutta scheme advances solutions in pseudo time. Turbulence closure is obtained using a cubic, high Reynolds number $\kappa-\varepsilon$ model with variable $\mathrm{C} \mu{ }^{20}$ While higherorder turbulence schemes like the Reynolds-stress turbulence model (RSTM) have been demonstrated to more accurately reproduce physical and statistical features of turbulent flows ${ }^{14}$, the $\kappa-\varepsilon$ model is considered appropriate for this study given its reduced computational cost. The NCC has been extensively validated against a number of experimental datasets including low speed chemically reacting flows. ${ }^{7,19,21-23}$ All computations were executed on a high performance compute cluster, using 400 Intel Xeon cores operating at 2.93-GHz. Wall-times were on the order of 36 to 48 hours per sector design, neglecting data transfer and queuing overhead.

For stability, NCC computations were conducted using a staged approach, similar to that described in Ref. 21. Injector designs were first analyzed to quasi steady-state without reacting chemistry or liquid spray. For each nonreacting combustor simulation, solutions were acquired for the governing gas phase equations (continuity, momentum, energy and turbulence). For the time marching scheme, a CFL number of 0.7 was used. The $2^{\text {nd }}$ order 
dissipation coefficients $\left(\varepsilon^{2}\right)$ were allowed to float between $1 \times 10^{-4}$ and 0.2 . Fourth order damping coefficients $\left(\varepsilon^{4}\right)$ were set to 0.08 . The $k_{2}$ constant used to scale the second order dissipation gradient switch was fixed at 0.5 . Nonreacting simulations were terminated after either meeting a global mass imbalance criterion of $1 \times 10^{-2}$ for 1000 successive iterations, or exceeding 30,000 time steps. Mass imbalance was determined using Eq. (5).

$$
\mathrm{m}_{\mathrm{imb}}=\frac{\dot{\mathrm{m}}_{\mathrm{in}}-\dot{\mathrm{m}}_{\text {out }}}{\dot{\mathrm{m}}_{\mathrm{in}}}
$$

After quasi-convergence of the non-reacting flow field, liquid spray and artificial ignition sources were introduced into each simulation. NCC uses a Lagrangian liquid spray module ${ }^{24}$ coupled to the gas phase solver, which calculates flow, thermal and transport properties of polydisperse sprays. For all injectors, a three-dimensional hollow cone spray pattern was prescribed with full $60^{\circ}$ cone angle and $8^{\circ}$ cone thickness. Initial fuel injection velocity was assumed $25-\mathrm{m} / \mathrm{s}$ for all designs. Primary and secondary liquid breakup models in NCC were not used. Instead, an initial liquid particle size distribution was specified, with average Sauter mean diameter $\left(\mathrm{D}_{32}\right)$ given empirically by Eq. (6) and adopted from Ref. 15.

$$
\mathrm{D}_{32}=2.25 \sigma^{0.25} \mu_{\mathrm{L}}^{0.25} \dot{\mathrm{m}}_{\mathrm{L}}^{0.25} \Delta \mathrm{P}_{\mathrm{L}}^{-0.5} \rho_{\mathrm{A}}^{-0.25}
$$

$\sigma$ and $\mu_{\mathrm{L}}$ are the surface tension and dynamic viscosity of the fuel, respectively, $\dot{\mathrm{m}}_{\mathrm{L}}$ is the fuel mass flow rate per injector, $\Delta \mathrm{P}_{\mathrm{L}}$ is the injection pressure differential across the fuel nozzle, assumed $689-\mathrm{kPa}(100-\mathrm{psi})$, and $\rho_{\mathrm{A}}$ is the density of the atomization air. Fuel properties were based on an assumed fuel injection temperature of $315-\mathrm{K}$. The polydisperse spray was defined using 10 discrete droplet size groups, assumed to follow a Gaussian distribution.

The single-step global chemistry mechanism in Table 4, which is based on kinetic rates for propane, was applied by adjusting the input chemistry parameters of NCC. The Arrhenius rate coefficient for temperature was determined using Eq. (7), where $A$ is the pre-exponential factor, $n$ is the temperature ratio exponent, $E$ is the activation energy, $T$ is the temperature, $R$ is the universal gas constant, and $T_{0}$ is the absolute reference temperature.

$$
\mathrm{k}=\mathrm{A}\left(\frac{T}{T_{0}}\right)^{n} e^{-\left(\frac{E}{R T}\right)}
$$

It is important to note that a turbulence-chemistry interaction model was not used for any of the configurations analyzed in this study. ${ }^{\dagger}$ For single-step reacting simulations, the $2^{\text {nd }}$ order dissipation floor was set to $1 \times 10^{-5}$, and the $4^{\text {th }}$ order coefficients were adjusted to 0.065 . The CFL number was increased to 0.8. Each solution was converged again to near steady-state, terminating after either a mass imbalance goal of $1 \times 10^{-3}$ had been achieved for 750 consecutive iterations or the number of reacting time steps exceeded 20,000.

Finally, the detailed 15 species, 18-step reaction mechanism for $\mathrm{C}_{11} \mathrm{H}_{21}{ }^{\ddagger}$ in Table 5 was introduced which contained minor species $\mathrm{CO}$ and NO. NO in the reduced mechanism represents the family of nitrogen oxides including nitric oxide by Zeldovich ${ }^{25}$ reactions, prompt $\mathrm{NO}$ reactions by Fenimore ${ }^{26}$ and nitrogen oxide formation through nitrous oxide. The $2^{\text {nd }}$ order damping coefficient floor was again reduced to $1 \times 10^{-6}$ and the $4^{\text {th }}$ order dissipation coefficients were set to 0.05 . Each simulation was restarted, converging after the averaged combustor exit temperature maintained a steady-state value for 8000 successive iterations. Steady-state was defined as changing less than $\pm 0.5 \%$ during the 8000 step interval.

\begin{tabular}{lccc}
\hline \multicolumn{4}{c}{ Table 4: Single-Step Global Chemistry Model } \\
\hline \multicolumn{1}{c}{ Reaction } & A (mol-cm-sec-K) & $n$ & E (cal/mol) \\
\hline $4 \mathrm{C}_{12} \mathrm{H}_{23}+71 \mathrm{O}_{2} \rightarrow 48 \mathrm{CO}_{2}+46$ & $8.6 \times 10^{11}$ & 0.00 & $3.00 \times 10^{4}$ \\
$\mathrm{H}_{2} \mathrm{O}$ & & & \\
$\mathrm{GLO} / \mathrm{C}_{12} \mathrm{H}_{23} 0.10 /$ & & & \\
$\mathrm{GLO} / \mathrm{O}_{2} 1.65 /$ & & & \\
\hline
\end{tabular}

\footnotetext{
${ }^{\dagger}$ Given the prohibitive cost of running a Monte-Carlo turbulence-chemistry interaction model, laminar chemistry was considered a reasonable and practical engineering assumption.

* Note the 18-step mechanism uses $\mathrm{C}_{11} \mathrm{H}_{21}$ as the fuel surrogate rather than $\mathrm{C}_{12} \mathrm{H}_{23}$. A preprocessing routine was used to convert all $\mathrm{C}_{12} \mathrm{H}_{23}$ to $\mathrm{C}_{11} \mathrm{H}_{21}$ during the chemistry update process of NCC.
} 


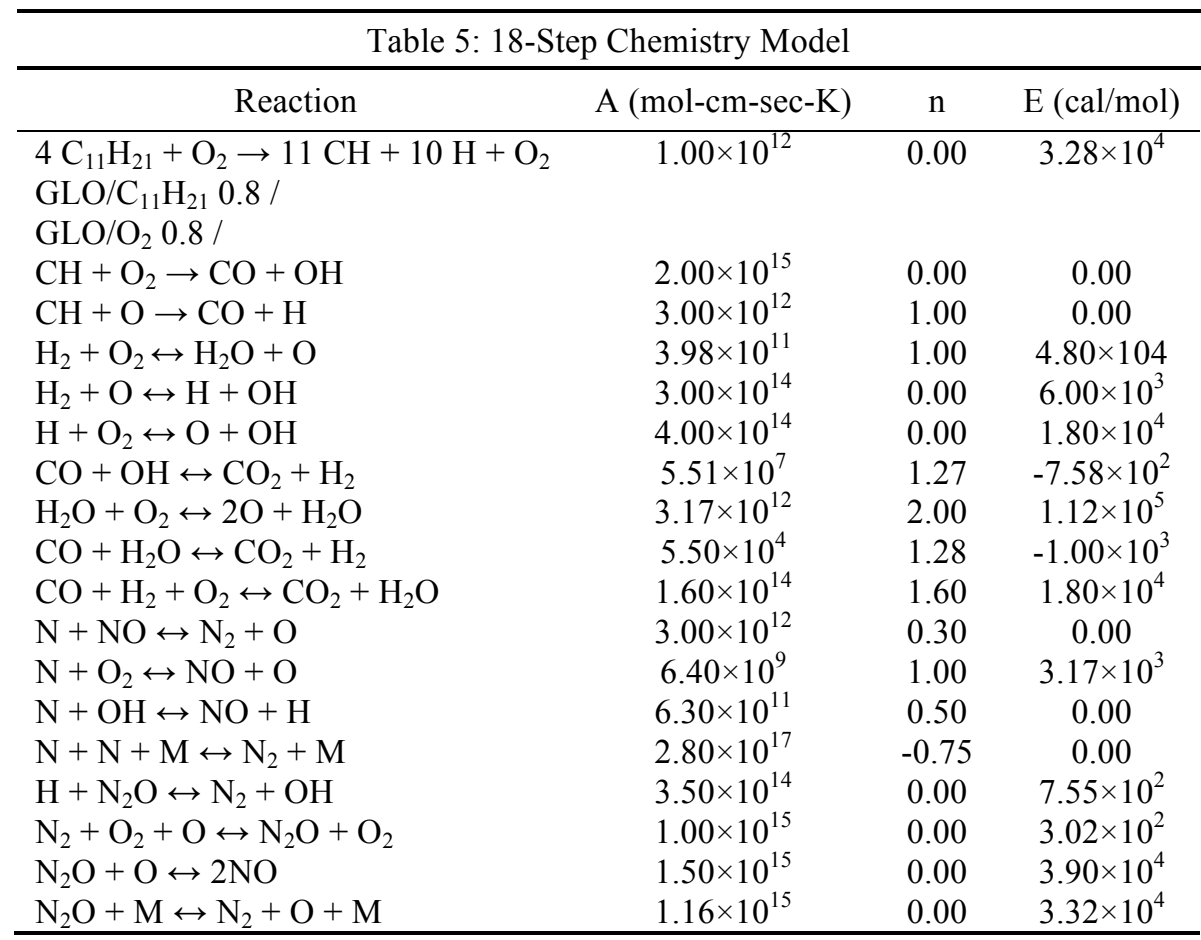

\section{Post-processing}

Automated post-processing scripts were developed to generate contour plots of primary flow field outputs. Additionally, these scripts computed and exported integrated boundary information from each solution file. Boundary data included axially averaged pressure, temperature, turbulent kinetic energy, unmixedness and minor species mass fractions.

\section{E. Software Integration}

The software OpenMDAO ${ }^{27}$ was used to manage the integration of all engineering codes applied in this study. OpenMDAO is an open-source, object-oriented framework developed to aid in the setup and solution of multidisciplinary design, analysis and optimization problems. In addition to basic software integration features, OpenMDAO provides resource allocation utilities that facilitate the execution of simulations over heterogeneous and geographically distributed computing networks. OpenMDAO also provides basic organizational assistance in bookkeeping volumes of data typical of large-scale analyses.

The framework is built on four base object classes: Component, Assembly, Driver, and Workflow.

- Component instances are objects that perform basic computations. Examples include the wrapped NPSS and NCC model instances.

- Driver instances control process iteration and include solvers and optimizers.

- Drivers contain a programming construct called Workflow, to which OpenMDAO components are added. The workflow determines and manages implicit process execution order based on data transfer between components.

- Assembly instances are container objects, which house components, drivers, and other assemblies. Assemblies define data transfer paths between components.

Using the base OpenMDAO classes, the analysis process in Fig. 10 was defined. Objects 1, 4, 5 and 6 are drivers, with independent workflows. All other objects were basic OpenMDAO components. Driver and component roles were defined as follows: 


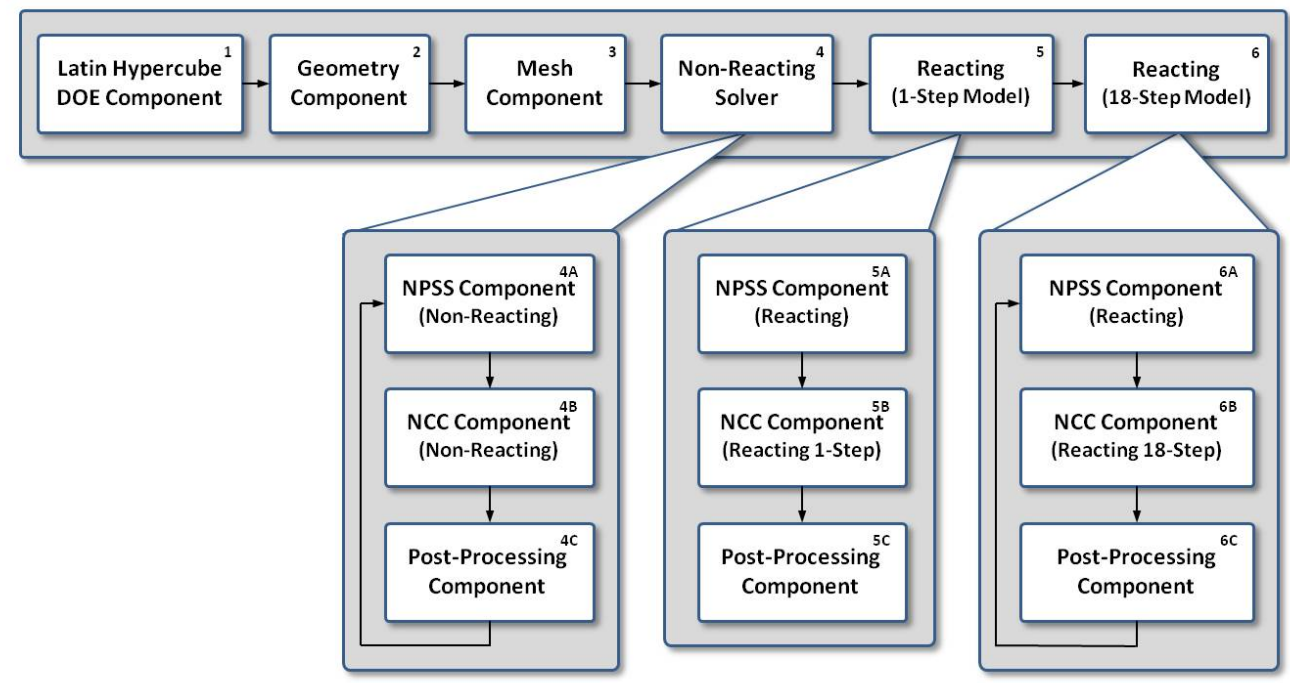

Figure 10: OpenMDAO analysis structure and process flow for the parametric LDI combustor study.

1) The Latin hypercube DOE driver (1) constructs an optimal Latin hypercube of combustor designs, given the set of injector design parameters and ranges previously defined in Table 1. For each sector configuration, the DOE component executes sub-components (2-6) contained in its workflow.

2) The Geometry component (2) launches a background CAD application instance, loads a baseline parametric LDI sector model, sets design parameters to match the current DOE case, generates a computational geometry and exports the geometry to a neutral file format.

3) The Mesh component (3) executes remotely by leveraging the OpenMDAO External Code interface. The mesh component transfers the computational geometry to a remote compute cluster, launches a background mesh application instance, loads the file created by Component 2, generates a geometry adaptive mesh, tags boundary surfaces and exports the mesh.

4) The Non-Reacting driver (4) is a fixed-point solver that iteratively executes sub-components 4A, 4B and 4C. As input, component $4 \mathrm{~A}$ accepts the geometric cross-sectional area of the current combustor case, cycle conditions $\left(\mathrm{T}_{3}\right.$, $V_{3}, P_{3}$ ) and assumes an initial pressure drop across the combustor. The f/a ratio is set to zero and the NPSS nonreacting component $(4 \mathrm{~A})$ is executed. NPSS performs a zero-dimensional mass and energy balance, computing flow variables near the sector inlet and exit boundaries. Output from $4 \mathrm{~A}$ includes $\mathrm{P}_{4}$, which is used to initialize component 4B. Component 4B then executes remotely. 4B manages the writing and transferring of flow solver input files to a computing cluster, executing the job through a batch queuing system, and returning all simulation output files to the localhost. Once 4B completes, component 4C executes on the localhost, post-processes simulation results and calculates an integrated average $\mathrm{P}_{3}$ over the combustor entrance plane. The post-processed $\mathrm{P}_{3}$ is returned to component 4A, and the driver workflow repeats until NPSS and NCC combustor pressure drops converge to within $\pm 0.1 \%$.

5) Driver 5 is similar to driver 4, but does not contain an iteration loop. Component $5 \mathrm{~A}$ accepts as input the target combustion temperature, $\mathrm{T}_{4}$. Execution of the reacting NPSS model computes the f/a required to achieve the desired $\mathrm{T}_{4}$, assuming $99.5 \%$ combustion efficiency and equilibrium chemistry. In addition, an adjusted exit pressure, $\mathrm{P}_{4}$, is calculated, taking into account Rayleigh pressure losses of roughly $0.1 \%$. Component $5 \mathrm{~B}$ restarts the gas phase flow solver from the previous non-reacting 4B solution, while activating the liquid spray solver and artificial ignition sources. Boundary conditions $\mathrm{T}_{3}$ and $\mathrm{P}_{3}$ are adjusted to match calculations from the previously tuned NPSS simulation (component 4A). Simulation results are returned to the localhost, where the Post-Processing component (5C) extracts and plots important flow field information. 
6) The workflow of driver 6 is similar to that of driver 5 . The primary difference exists in sub-component $6 \mathrm{~B}$, where the flow solver chemistry mechanism includes an augmented species list. Component 6 also includes a feedback loop that terminates when the average combustor exit temperature reaches steady state to within $\pm 0.5 \%$.

\section{Results and Discussion}

Results showing temperature, axial velocity, turbulent kinetic energy (TKE), unmixedness and spatial distribution of NO mass fraction have been provided in the Appendix for all 20 LDI sector configurations. While unmixedness and turbulent kinetic energy are not direct objective outputs, they may prove useful for helping produce analytical approximations of actual objectives in future research. The spatial unmixedness parameter was adopted from Ref. 28 and calculated using Eq. (8).

$$
U_{S}=\frac{\left|y_{i}-y^{*}\right|}{y^{*}}
$$

$y_{i}$ is the local fuel mass fraction of cell $i$ and $y^{*}$ is the maximum fully mixed mass fraction, given by the mass of fuel entering the domain divided by the total mass of all species entering the domain. When a system is perfectly mixed, $U_{S}$ approaches zero. When fuel and air are perfectly segregated, $U_{S}$ approaches unity. An unmixedness value of 1 corresponds to either the existence of fuel or air (but not both) within a given cell. Normalizing by $y^{*}$ permits direct comparison of unmixedness between designs, independent of mass-flow rate.

Table 6 summarizes design parameter inputs and objective outputs for each combustor configuration. For completeness, average Sauter mean diameters have also been included, but were computed directly using Eq. (6).

\begin{tabular}{cccccccccc}
\hline \multicolumn{10}{c}{ TABLE 6: Optimal Latin Hypercube Design Matrix Including Objective Outputs } \\
\hline $\begin{array}{c}\text { Design } \\
\#\end{array}$ & $\begin{array}{c}\mathrm{X}_{1} \\
(\mathrm{~cm})\end{array}$ & $\begin{array}{c}\mathrm{X}_{2} \\
(\mathrm{deg})\end{array}$ & $\begin{array}{c}\mathrm{X}_{3} \\
(\mathrm{deg})\end{array}$ & $\begin{array}{c}\mathrm{X}_{4} \\
(\#)\end{array}$ & $\begin{array}{c}\mathrm{D}_{32} \\
(\mu \mathrm{m})\end{array}$ & $\begin{array}{c}\Delta \mathrm{P} \\
(\%)\end{array}$ & $\begin{array}{c}\text { Length } \\
(\mathrm{cm})\end{array}$ & $\begin{array}{c}\text { Non- } \\
\text { Uniformity }\end{array}$ & $\begin{array}{c}\text { EINO }_{\mathrm{x}} \\
(\mathrm{g} / \mathrm{kg})\end{array}$ \\
\hline 1 & 2.318 & 40.37 & 49.75 & 6 & 21.9 & 2.709 & 5.66 & 4.06 & 3.32 \\
2 & 2.635 & 70.39 & 42.25 & 6 & 23.4 & 4.425 & 3.64 & 51.45 & 3.00 \\
3 & 2.508 & 44.99 & 33.25 & 7 & 22.8 & 2.566 & 6.49 & 4.82 & 3.39 \\
4 & 2.572 & 56.54 & 36.25 & 4 & 23.1 & 3.166 & 6.99 & 25.90 & 8.14 \\
5 & 2.191 & 63.46 & 37.25 & 7 & 21.3 & 4.221 & 3.01 & 2.72 & 2.51 \\
6 & 2.127 & 61.15 & 28.75 & 4 & 21.0 & 3.344 & 3.79 & 11.79 & 4.43 \\
7 & 2.064 & 65.77 & 34.75 & 5 & 20.7 & 3.787 & 7.55 & 95.26 & 3.24 \\
8 & 2.381 & 51.91 & 43.75 & 5 & 22.2 & 2.292 & 3.44 & 50.21 & 5.52 \\
9 & 2.000 & 58.84 & 45.25 & 5 & 20.4 & 3.339 & 4.85 & 48.47 & 3.21 \\
10 & 1.810 & 47.30 & 25.75 & 7 & 19.4 & 2.931 & 3.28 & 4.70 & 2.64 \\
11 & 2.254 & 79.63 & 48.25 & 6 & 21.6 & 5.409 & 2.32 & 52.25 & 2.14 \\
12 & 3.016 & 42.68 & 46.75 & 6 & 25.2 & 2.673 & 5.41 & 3.86 & 4.95 \\
13 & 2.826 & 38.06 & 30.25 & 8 & 24.2 & 2.412 & 6.99 & 19.20 & 5.71 \\
14 & 2.889 & 49.61 & 51.25 & 8 & 24.5 & 3.963 & 10.85 & 1.61 & 2.86 \\
15 & 2.445 & 81.94 & 52.75 & 8 & 22.5 & 7.104 & 2.96 & 28.80 & 1.96 \\
16 & 2.762 & 77.32 & 54.25 & 5 & 23.9 & 5.180 & 8.17 & 3.18 & 2.94 \\
17 & 1.937 & 72.70 & 39.25 & 4 & 20.0 & 4.057 & 5.43 & 123.14 & 3.18 \\
18 & 2.699 & 68.08 & 31.75 & 8 & 23.7 & 5.583 & 2.37 & 0.55 & 2.03 \\
19 & 1.873 & 54.23 & 40.75 & 7 & 19.7 & 3.331 & 3.74 & 3.27 & 2.38 \\
20 & 2.953 & 75.01 & 27.25 & 4 & 24.7 & 4.322 & 3.15 & 1.10 & 3.61 \\
\hline
\end{tabular}

Figure 11 plots the complete objective space. Given the high dimensionality and sparseness of data, a representative Pareto surface was not extracted. Optimal designs tend to fall near the origin of each graph. Of particular interest is configuration 10, which exhibits low output function values in all four objectives. While not optimal in any given output metric, case 10 is consistently near the top $25^{\text {th }}$ percentile of designs in all dimensions. Also worth noting is design 19, which has $\mathrm{X}_{1}$ and $\mathrm{X}_{4}$ inputs similar to case 10. Distinguishing differences include a $15 \%$ larger vane angle and $58 \%$ higher venturi half angle. The higher vane angle produces a stronger recirculating vortex, which leads to a more uniform flame structure as measured across adjacent injectors. As a downside, pressure is compromised due to higher turbulence levels and greater flow separation inside the venturi. The design 
differences also lead to a small but evident decrease in $\mathrm{EINO}_{\mathrm{x}}$. Similar trade-offs are common throughout the design space, and improvements to any one objective commonly cause degradation in another.
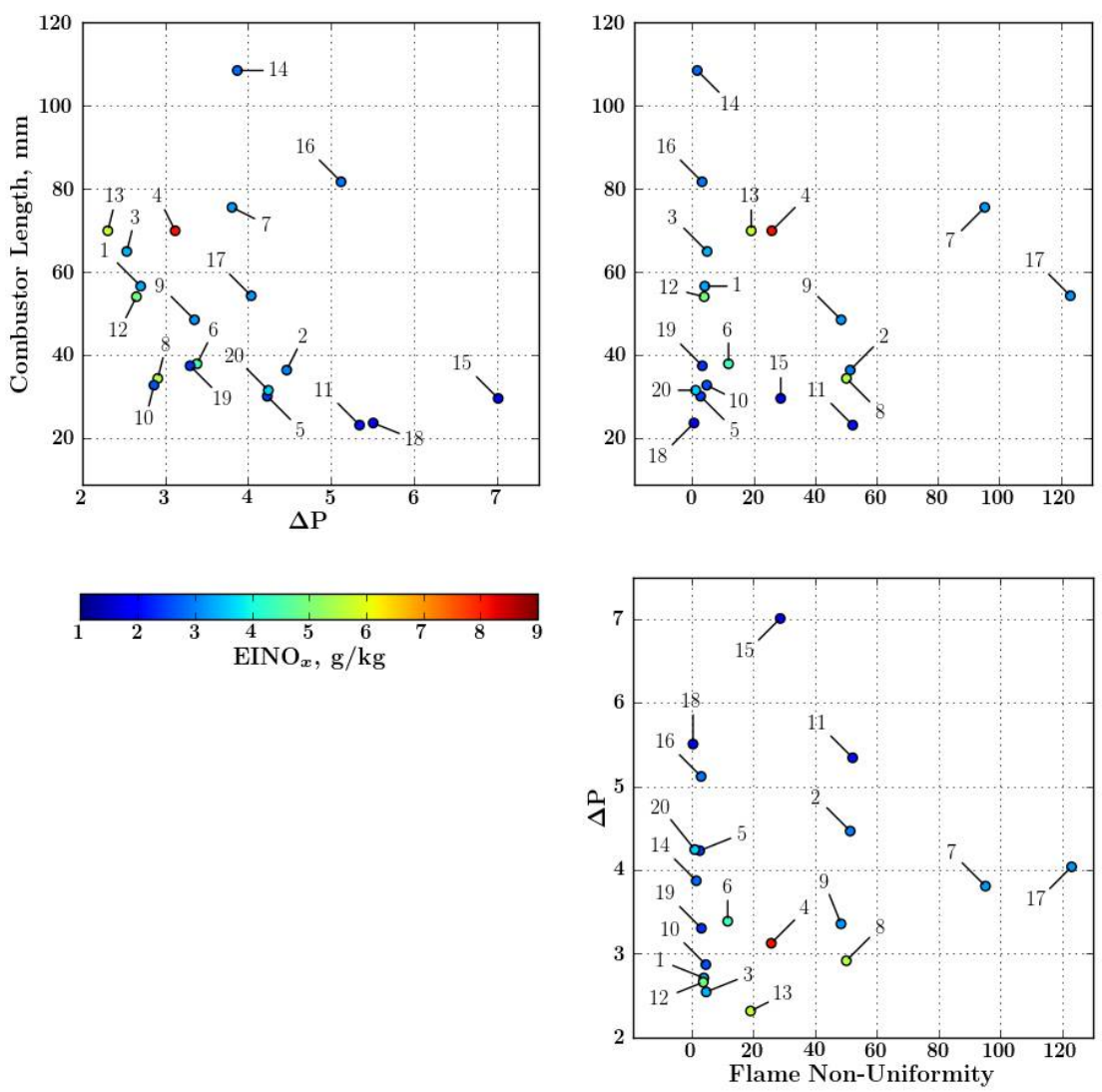

Figure 11. Objective space plots for all four design objectives.

From analysis of the design space, a series of notable trends were observed. In general, data suggest complex coupling between design parameters that is challenging to qualitatively describe given the limited number of DOE sample cases.

1) Combustor $\Delta \mathrm{P}$ is significantly influenced by swirler vane angle and the number of swirler blades per injector. Injector designs with high solidity tend to experience larger static pressure losses. Potentially offsetting $\Delta \mathrm{P}$ contributions arise from changes to injector module diameter and venturi angle. With large venturi angles, pressure losses arise from flow separation near the venturi throat and exit. A proportional relationship between $\triangle \mathrm{P}$ and TKE is also captured in many simulation results.

2) Several combinations of parameters produce non-uniform, unstable flame structures, defined by large, irregular temperature gradients near the injector region. For example, see designs 4, 7, 8, 9 and 17 in Figs. 18 and 19 of the Appendix. These configurations all share two common characteristics: 1) a low number of swirler blades, and 2) vane angles in the range of 56 to 72 degrees. All injector designs with vane angles less than or greater than this range appear to produce inherently regular flames. This suggests a high sensitivity to vane angle on injector performance, and bimodal relationship between vane angle and flame uniformity. Three cases from the DOE have injector designs with vane angles between 56 and 72 degrees that do not exhibit highly irregular flame characteristics. (See cases 5, 6 and 18 in the Appendix). Cases 5 and 18 contain a comparatively large number of swirler blades along with low venturi half angles. This combination appears to mitigate potential instabilities attributed to vane angles in the normally unstable regime. The behavior of case 6 is less easily explained, as the design only contains 4 swirler blades. Uniquely, case 6 features a comparatively shallow venturi angle, which seems alone sufficient to regularize the flame structures across injectors. 
3) Fuel-air coupling plays a dominant role in overall combustion performance. The initial liquid fuel injection settings for each sector differed by only minor variations in average droplet size. Despite this, notable spray pattern differences are evident in Fig. 28 of the Appendix. These differences are largely attributed to the complex vortex structures that consume the fuel spray. An aerodynamically stabilized flame front relies on a radial and axial balance of momentum between the liquid and gas phase streams. The size, location, and strength of the recirculation zone affect the entrainment of fuel droplets and overall effectiveness of the combustion process. A strong, off-centered and non-uniform reverse flow region leads to poor spray entrainment and is particularly detrimental to flame zone stability. A not well-behaved spray distribution also leads to insufficient mixing and produces localized fuel-rich regions near the flame holding sites.

4) Destructive interferences from adjacent injectors are apparent in several simulations and impact the fuel spray distribution. Cases with well-defined, conical spray patterns exhibit higher flame uniformity across injectors.

5) LDI module diameter and injector spacing appear to have a negligible impact on TKE.

6) The majority of cases suggest wall effects are non-trivial and may restrict the downstream convection of flames. For example, the size and magnitude of the central injector recirculation zone appears suppressed in cases 11, 13, 14, 15, and 16 in Figs. 22 and 23 of the Appendix. This suppression then contributes to an elongated flame structure, evident for the center injector only.

7) The formation of $\mathrm{NO}_{\mathrm{x}}$ appears to be a highly localized phenomenon that does not track exclusively with any single design parameter or metric. As expected, $\mathrm{NO}_{\mathrm{x}}$ does appear to correlate with temperature. For example, case 4 contains a high temperature region located downstream of the central injector, which serves as a significant $\mathrm{NO}_{\mathrm{x}}$ source. See Figs. 18 and 24 in the Appendix.

\section{Surrogate Modeling}

A meta-model was generated to predict averaged CFD solution outputs based on the four injector design parameters, $\mathrm{X}_{1}$ through $\mathrm{X}_{4}$. The term meta-model is used here to represent a collection of surrogate models developed to estimate reduced outputs from CFD. With the use of discrete design variables and limited DOE sample size, surrogate model over-fitting was a valid concern. Artificial neural network (ANN) models are capable of describing functions with discrete inputs, but are susceptible to large interpolation errors when used to represent sparse, non-smooth functions. Kriging is another commonly applied surrogate technique, but also known to have difficulty estimating responses with discrete inputs. For these reasons, response surface equations (RSEs) were considered preferred and calculated, when possible, using a least squares regression to fit the computational output data. RSE coefficients also provide insight into model behavior and offer a more intuitive understanding of the main and interaction effects related to primary input parameters.

A $2^{\text {nd }}$ order RSE was created to predict combustor $\Delta \mathrm{P}$ from $\mathrm{X}_{1}$ through $\mathrm{X}_{4}$. The response is given in Eq. (9), with coefficients listed in Table 7. Figure 12 demonstrates the accuracy of the RSE in predicting CFD calculated $\triangle \mathrm{P}$ for all 20 sector configurations. The linear R-squared fit was near 1, indicating the model is appropriate for estimating pressure losses for similar combustor configurations within the bounds of the design space. Extrapolating beyond the design variable ranges in Table 1 is not recommended.

$$
\Delta P=\beta_{0}+\sum_{i=1}^{4} \beta_{i} X_{i}+\sum_{i=1}^{4} \beta_{i i} X_{i}^{2}+\sum_{i<j} \sum_{j=2}^{4} \beta_{i j} X_{i} X_{j}
$$

\begin{tabular}{|c|c|c|c|c|}
\hline \multicolumn{5}{|c|}{ TABLE 7: Coefficients for $2^{\text {nd }}$ Order RSE $\Delta P$ Correlation } \\
\hline$\beta_{0}$ & $\beta_{1}$ & $\beta_{2}$ & $\beta_{3}$ & $\beta_{4}$ \\
\hline 4.007813 & 1.031201 & -0.000223 & -0.067925 & -1.294743 \\
\hline$\beta_{11}$ & $\beta_{12}$ & $\beta_{22}$ & $\beta_{13}$ & $\beta_{23}$ \\
\hline-0.294225 & -0.003989 & 0.000491 & 0.015871 & -0.001122 \\
\hline$\beta_{33}$ & $\beta_{14}$ & $\beta_{24}$ & $\beta_{34}$ & $\beta_{44}$ \\
\hline 0.001877 & 0.007295 & 0.012589 & -0.006630 & 0.088787 \\
\hline
\end{tabular}




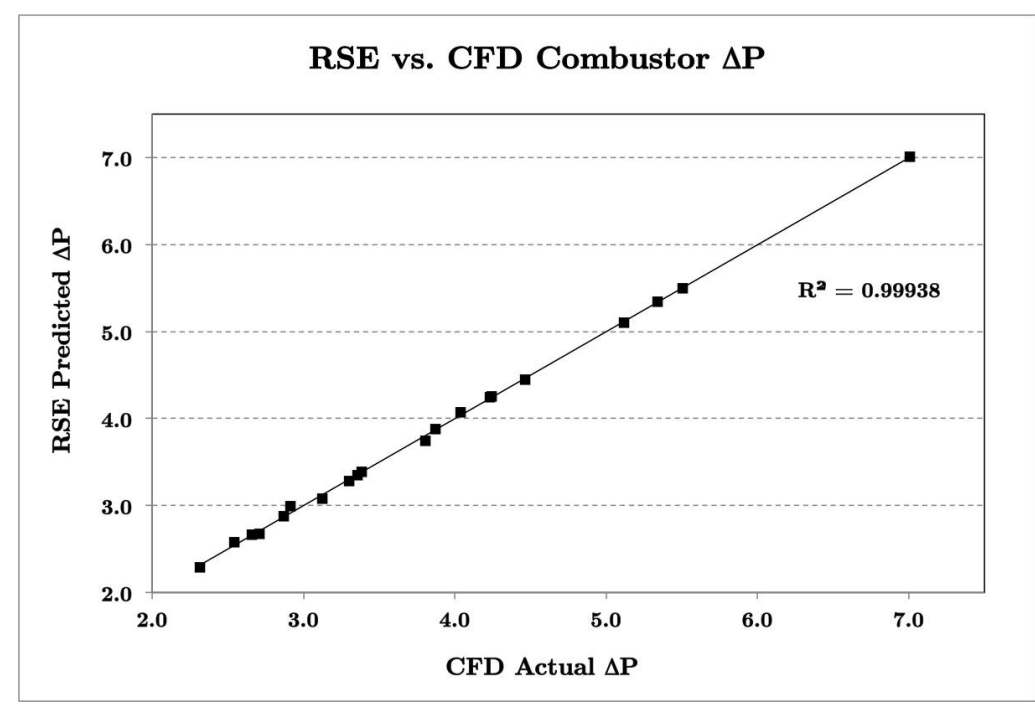

Figure 12. RSE predicted versus CFD actual combustor pressure drop.

Similarly, a $2^{\text {nd }}$ order RSE was developed to predict $\mathrm{EINO}_{\mathrm{x}}$ at the downstream exit plane of each combustor configuration. Again, the equation accepts as input design variables $\mathrm{X}_{1}$ through $\mathrm{X}_{4}$. The RSE form is given by Eq. (10), with coefficients listed in Table 8.

$$
\mathrm{EINO}_{x}=\beta_{0}+\sum_{i=1}^{4} \beta_{i} X_{i}+\sum_{i=1}^{4} \beta_{i i} X_{i}^{2}+\sum_{i<j} \sum_{j=2}^{4} \beta_{i j} X_{i} X_{j}
$$

\begin{tabular}{|c|c|c|c|c|}
\hline \multicolumn{5}{|c|}{ TABLE 8: Coefficients for $2^{\text {nd }}$ Order RSE EINO ${ }_{x}$ Correlation } \\
\hline$\beta_{0}$ & $\beta_{1}$ & $\beta_{2}$ & $\beta_{3}$ & $\beta_{4}$ \\
\hline-9.886183 & 21.497576 & 0.020317 & 0.157992 & 3.999729 \\
\hline$\beta_{11}$ & $\beta_{12}$ & $\beta_{22}$ & $\beta_{13}$ & $\beta_{23}$ \\
\hline-1.805466 & -0.085743 & -0.001051 & 0.010985 & 0.004447 \\
\hline$\beta_{33}$ & $\beta_{14}$ & $\beta_{24}$ & $\beta_{34}$ & $\beta_{44}$ \\
\hline-0.004803 & -1.092417 & 0.014563 & -0.010407 & 0.448364 \\
\hline
\end{tabular}

Figure 13 shows the RSE predicted verses $\mathrm{NCC}$ calculated $\mathrm{EINO}_{\mathrm{x}}$ for all 20 sector designs. The linear R-squared fit is around 0.94, indicating the model compares reasonably well with CFD. This RSE is considered useful for predicting general trends for conceptual design purposes, but not accurate enough to completely replace detailed chemistry and CFD. The RSE uncertainty is especially large for $\mathrm{EINO}_{\mathrm{x}}$ values above 6-g/kg, where limited data exists on which to fit. The model is considered more appropriate for $\mathrm{EINO}_{\mathrm{x}}$ predictions less than $6-\mathrm{g} / \mathrm{kg}$, where a higher concentration of the DOE data is represented. Again, the RSE is valid for inputs within the ranges listed in Table 1.

Increasing the number of simulated combustor configurations and variety of operating conditions could greatly improve the accuracy and robustness of the RSE surrogate models presented here. The primary purpose, however, is to demonstrate proof-of-concept for constructing a meta-model driven by reduced reacting CFD solution outputs. Extensions of these models to incorporate additional operational inputs, including f/a, $\mathrm{P}_{3}$, and $\mathrm{T}_{3}$ would greatly enhance their overall value and utility. Such enhancements are considered potential future work and beyond the scope of this study. 


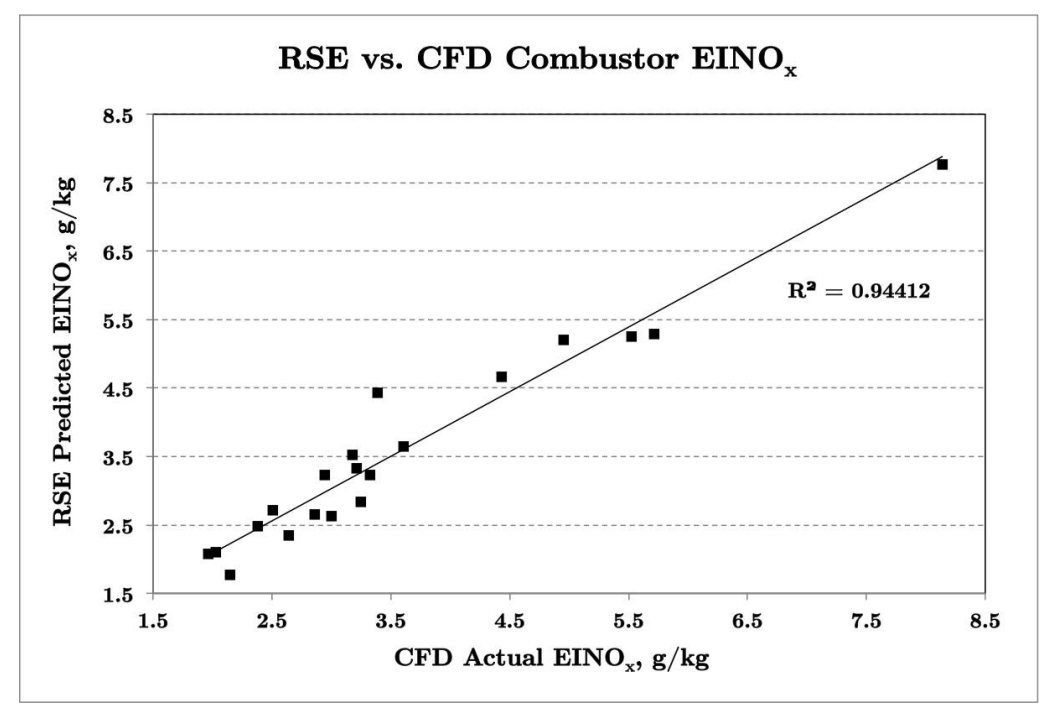

Figure 13. RSE predicted versus CFD actual combustor EINO .

Attempts were made to develop predictive RSE models for axially averaged combustor temperature and NO mass fractions with limited success. Instead, ANN models with 1 hidden layer, 3 nodes and 5-fold cross validation were constructed. A penalty method was used to mitigate the likelihood of over-fitting. In addition to $\mathrm{X}_{1}$ through $\mathrm{X}_{4}$, axial distance from the combustor dome was added as an independent input variable for ANN training. Figure 14 demonstrates model performance for cross-section averaged combustor static temperatures. Figure 15 contains similar information for the $\mathrm{NO}$ mass fraction. R-squared values of 0.9 and 0.93 were realized for the temperature and NO neural networks, respectively.

The ANN for axially averaged temperature produced a smooth fit over the entire design space with indications of over-fitting not apparent. The model under predicts average temperature by as much as $10 \%$ and over predicts by up to $5 \%$. Fairly good agreement is achieved for temperatures between $1600-\mathrm{K}$ and $1900-\mathrm{K}$. This average temperature range represents the region including and downstream of the fully developed flame zone.

The ANN developed to estimate axially averaged NO mass fraction displays some indications of over-fitting. This is especially evident for axial locations with small NO mass fractions, where the ANN equation may potentially predict negative values. The errors associated with predicted NO are considerably larger than those for temperature. Despite these downsides, the model does capture relative design space trends, which is the current goal. The addition of more input data would likely produce a higher accuracy and more reliable fit.

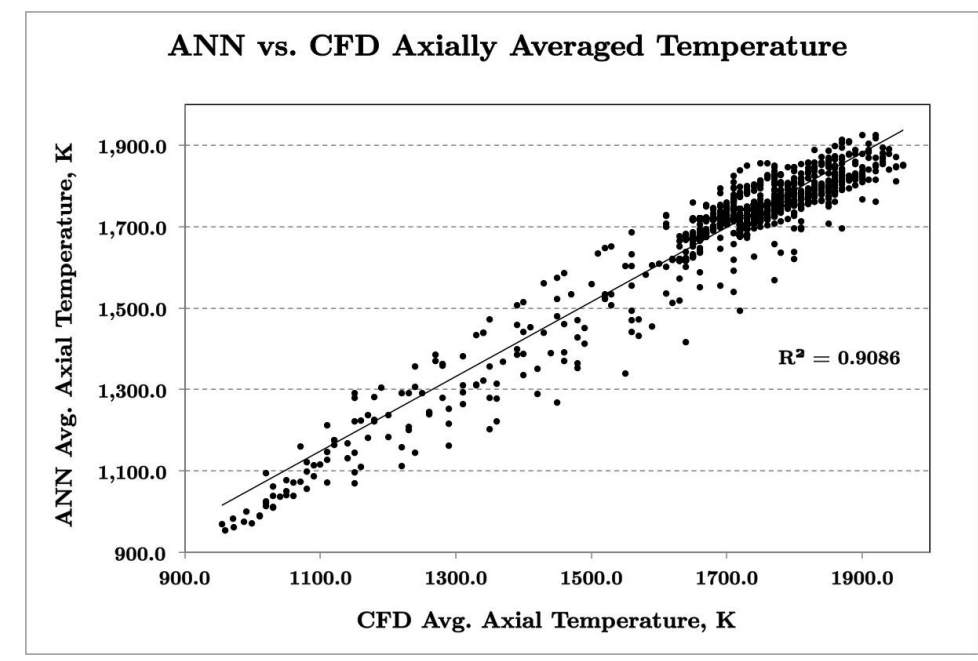

Figure 14. ANN (predicted) versus CFD (actual) axially averaged temperature. 


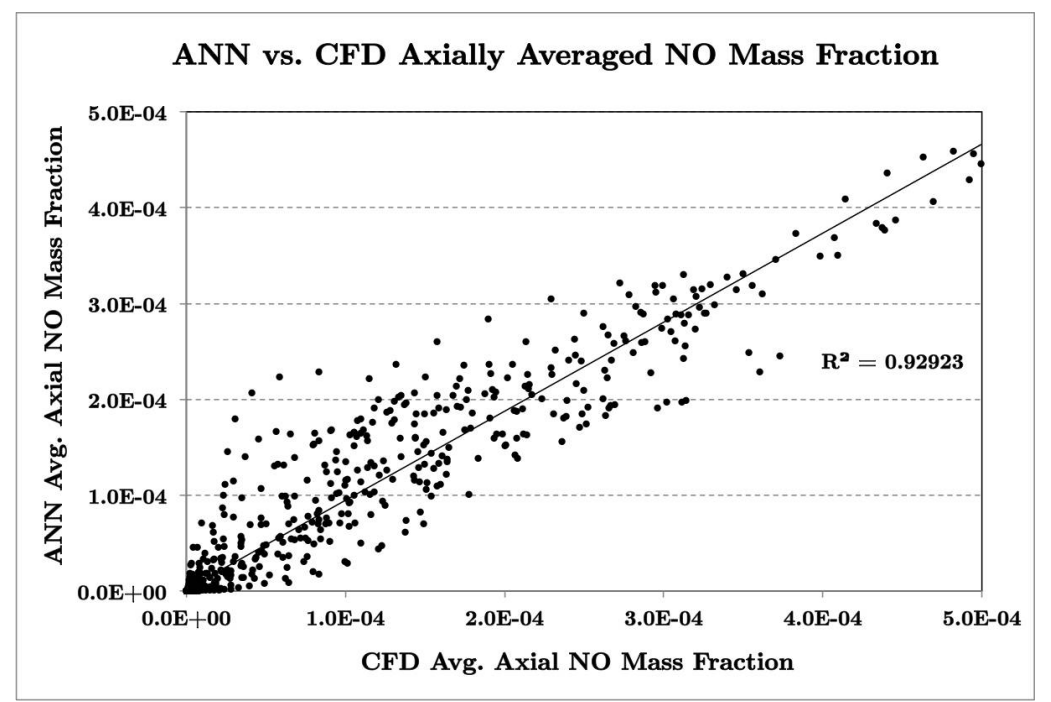

Figure 15. ANN (predicted) versus (CFD) axially averaged NO mass fraction.

\section{Uncertainty Analysis}

Given the coupling of the multi-phase solvers, artificial dissipation settings, and specified solver tolerances, solutions exhibited small but noticeable oscillatory convergence behavior. The majority of simulation outputs converged to within $\pm 1 \%$ of a mean value. As an example, average combustor exit temperatures were recorded for all combustor simulations over the final 10,000 iterations. Those averages along with uncertainty bounds are displayed in Fig. 16. Uncertainty bounds represent the full range of average exit temperatures encountered over the last 10,000 time steps. The temperature variation between combustor designs is not expected, given the f/a was fixed to produce a $\mathrm{T}_{4}$ of $1735.5-\mathrm{K}$ for all configurations. This $\mathrm{f} / \mathrm{a}$ assumed equal combustion efficiencies of $99.5 \%$ for all 20 designs. This assumption was not necessarily accurate, as fuel injector performance contributed to significant differences in average exit temperatures. Cases with temperatures that exceed the equilibrium flame temperature by as much as $1.4 \%$ are attributed to the use of a reduced reaction mechanism. The reduced chemistry assumption neglects a number of minor species involved in endothermic reactions steps. Errors associated with volume discretization and machine precision offer secondary sources of uncertainty.

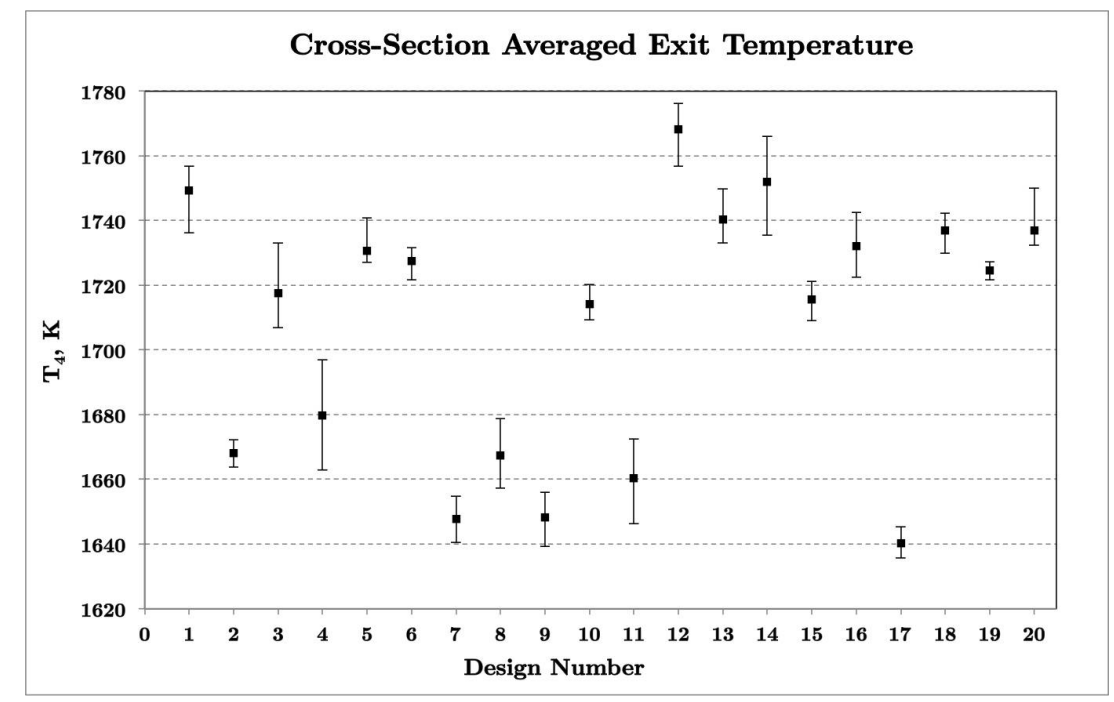

Figure 16. Cross-section averaged exit temperatures for all 20 DOE cases, including uncertainty.

Similarly, Fig. 17 contains the same uncertainty information for $\mathrm{EINO}_{\mathrm{x}}$ measured at the exit of each combustor. Uncertainty was typically less than 5\%, and significantly less than the variation in $\mathrm{EINO}_{\mathrm{x}}$ between designs. 


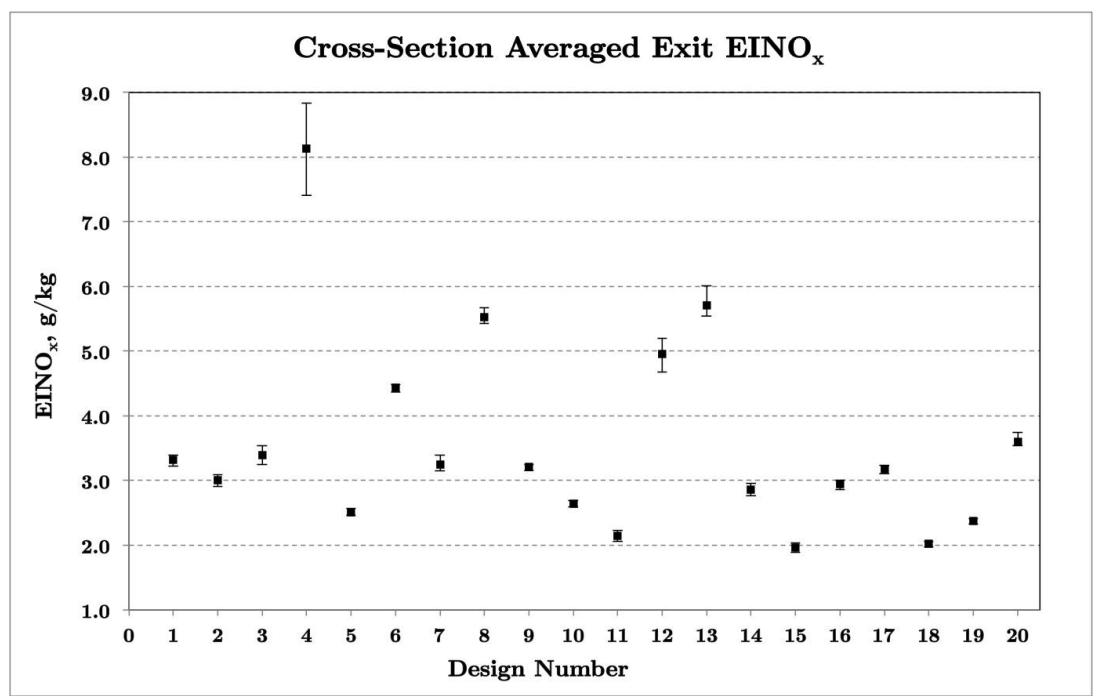

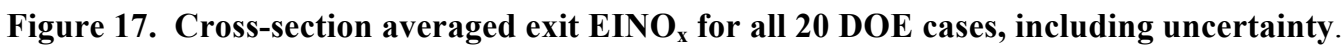

\section{Conclusions}

Stringent emission and fuel reduction demands call for improvements in low-order modeling to expedite the conceptual gas-turbine combustor design process. Understanding the role of combustor geometry, flow physics, reactive chemistry and cycle conditions is critical for advancing aviation combustion strategies beyond the current state-of-the-art. The objective of the present effort was to define a unified link between LDI geometry specific design parameters, flow field responses, and emissions, encapsulating important trends in a generalized meta-model. This research serves as a proof of concept for developing surrogate approximations directly from steady-state chemically reacting RANS simulations. Additionally, a process has been developed to streamline the execution of multi-phase reacting CFD, reducing though-put time from months to days. This alone enables a significant advancement in the use of high-fidelity simulations to drive conceptual design for new combustion systems.

The performed study provides qualitative and quantitative assessment of swirl-venturi LDI combustion fundamentals. Qualitative trends indicate two regimes exist for swirl-stabilized flames, largely dictated by swirler vane angle. Vane angles between $56^{\circ}$ and $72^{\circ}$ were found to generate inherently irregular flames, while angles outside this range resulted in more uniform combustion. Shallow venturi angles and high injector solidity offset instabilities in configurations with naturally unstable swirl characteristics. Fuel-air coupling along with recirculation zone strength and size were discovered to be important factors contributing to fuel injector performance. Quantitatively, RSE and ANN models were developed to approximate important CFD outputs with varying levels of success. Pressure loss correlations were found to accurately model the design space, while temperature and emission models contained larger uncertainties, that may still prove acceptable for conceptual design.

Of the 20 combustor sectors studied, all produced quasi-steady solutions with residual mass imbalances of approximately $1 \%$ or less. Grid resolution is one contributing factor, which may be mitigated through individual grid refinement studies, or local error-based mesh adaptation. Alternately, some injector designs may inherently produce unsteady flow characteristics, including vortices and wakes. While such features may be better resolved through time-accurate simulations, the computational cost remains too significant for practical conceptual engineering purposes. Lastly, non-ideal coupling of the liquid and gas-phase flow solvers as well as stochastic injection introduced known artificial unsteadiness into each simulation. Despite these sources of error, a best effort was made to characterize uncertainties associated with averaged simulation outputs.

Near future plans involve advancing the geometric models and numerical schemes to bring the analysis closer to representing actual combustor hardware. Given the high level of automation achieved, the developed process is prime for more advanced optimization studies, including surrogate-driven adaptive sampling methods.

\section{Appendix}

Figures 18 through 28 contain contour plots of key solution outputs, showing side view images extracted along the centerline, and axial images extracted in 5-mm increments where the zero location denotes the injector exit plane. Design input parameters are listed above each set of case images. 


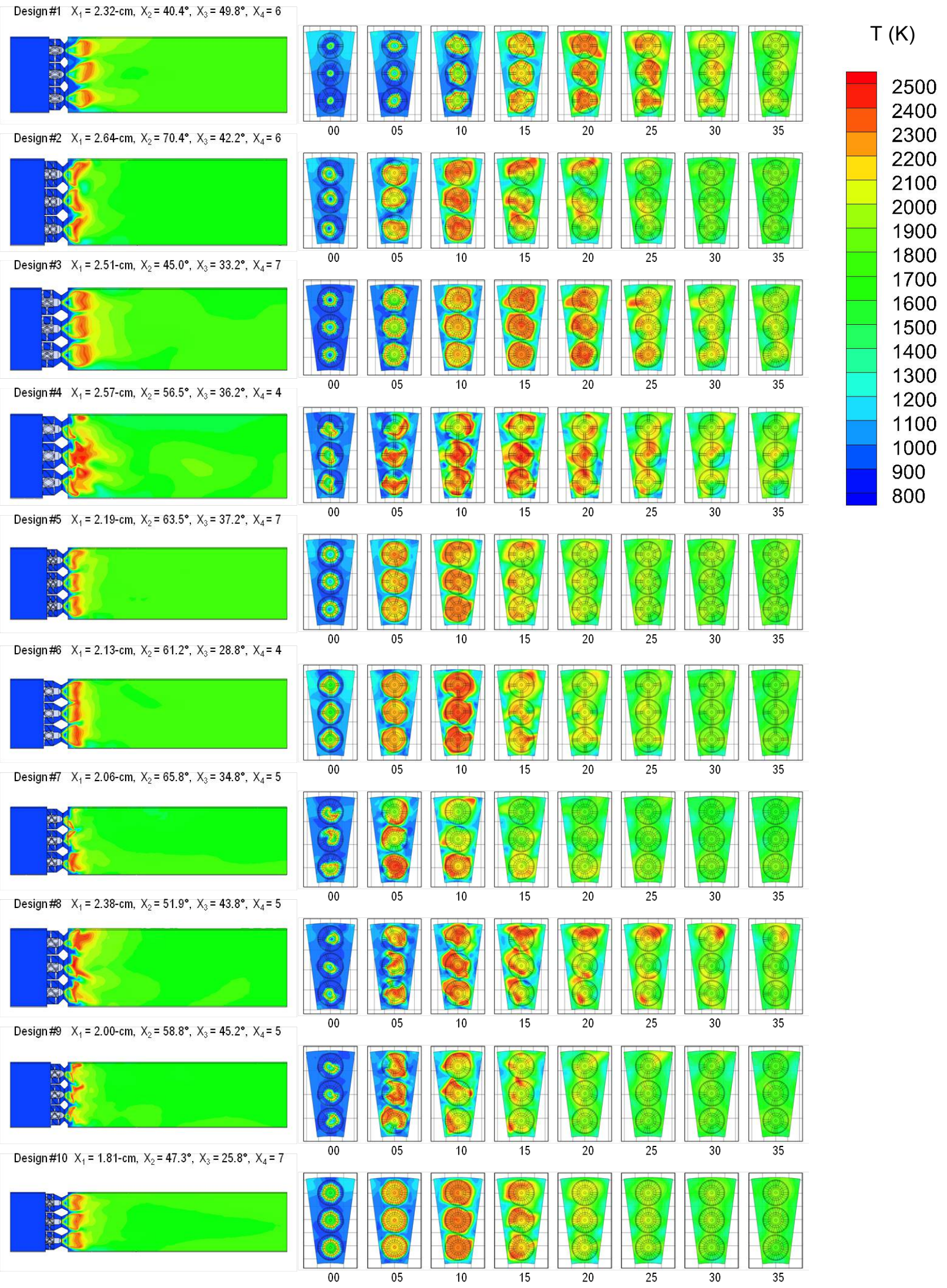

Figure 18. Static temperature contours for configurations 1 through 10.

American Institute of Aeronautics and Astronautics 


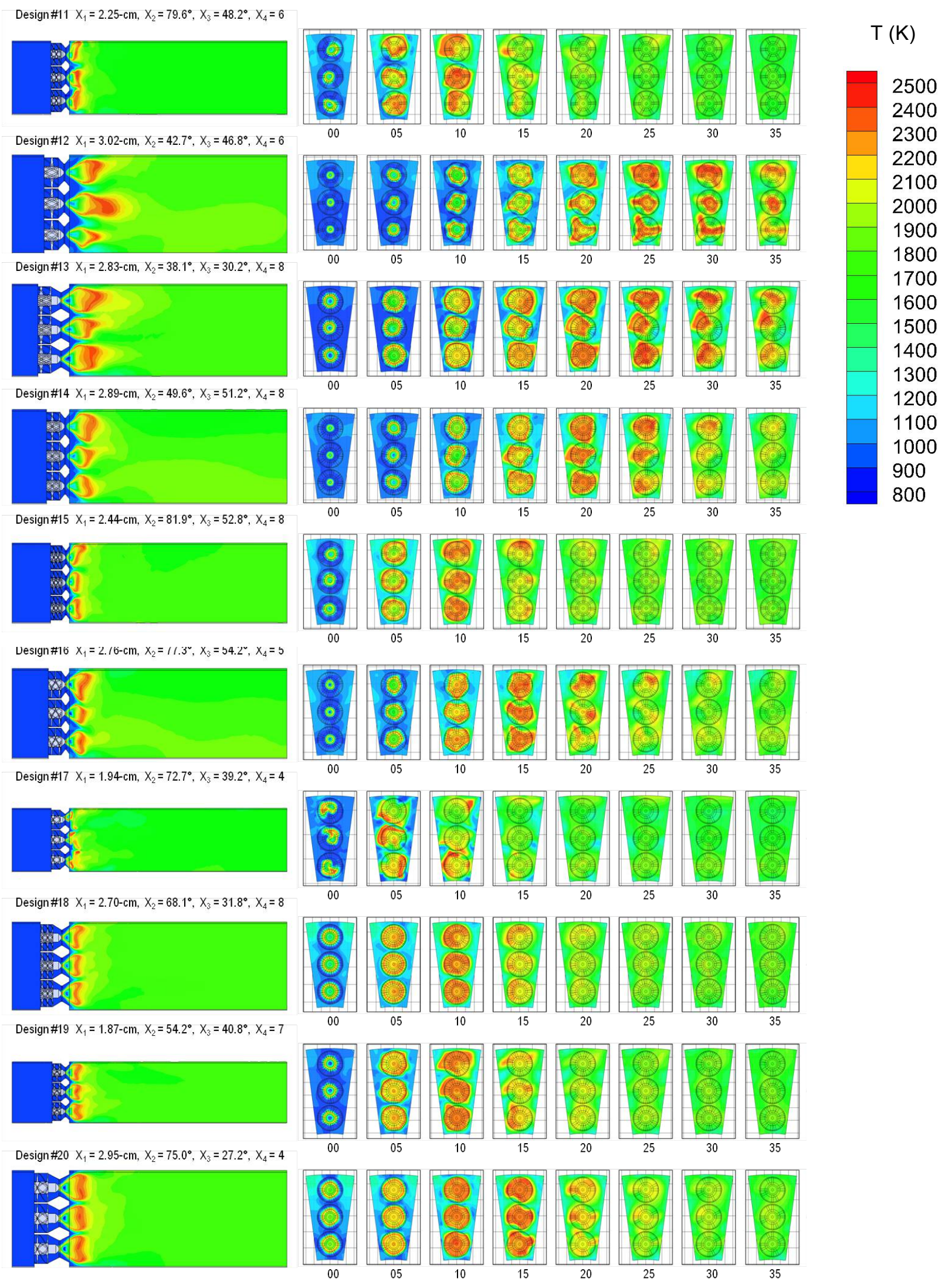

Figure 19. Static temperature contours for configurations 11 through 20. 


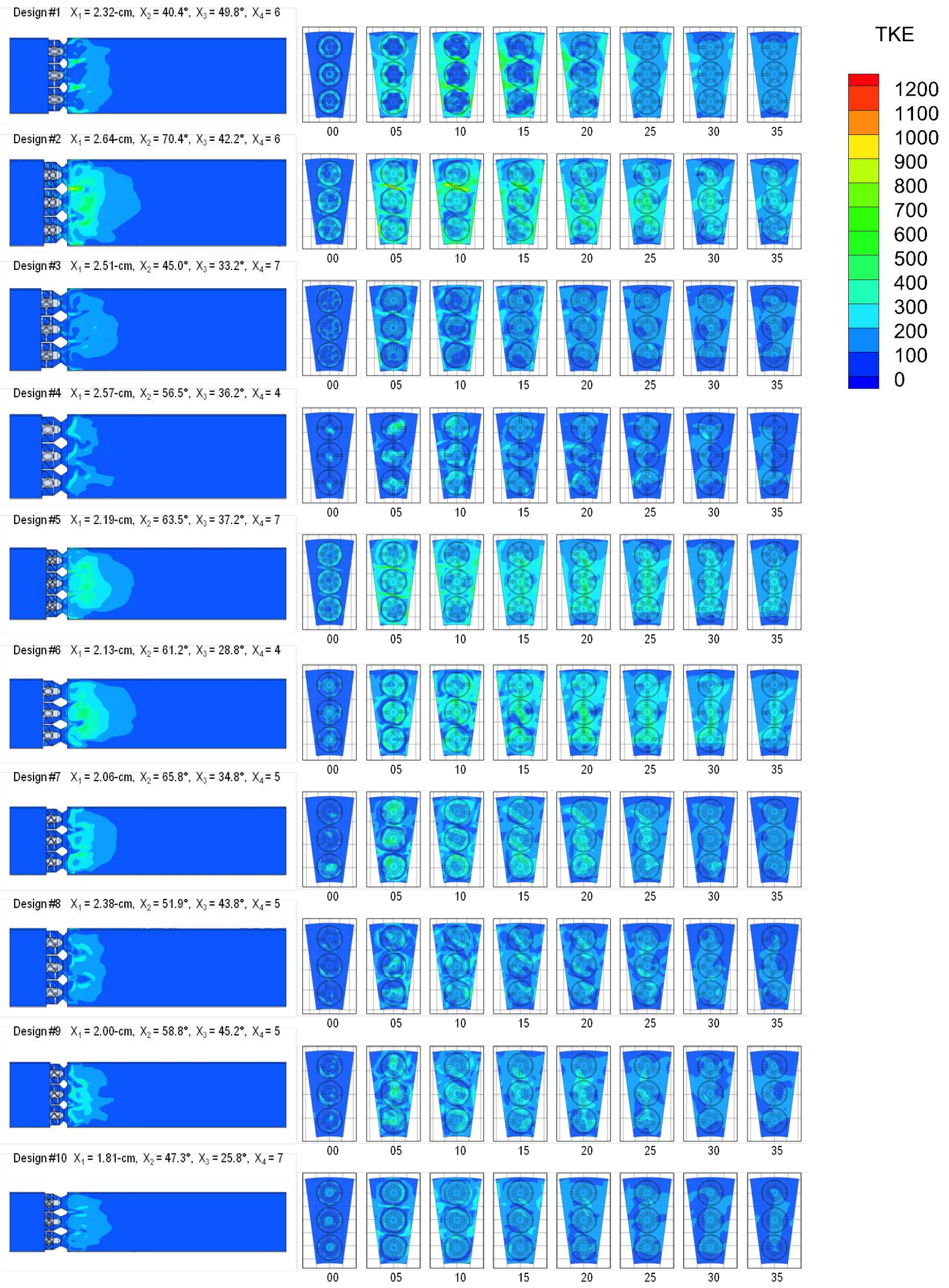

Figure 20. Turbulent kinetic energy contours for configurations 1 through 10. 


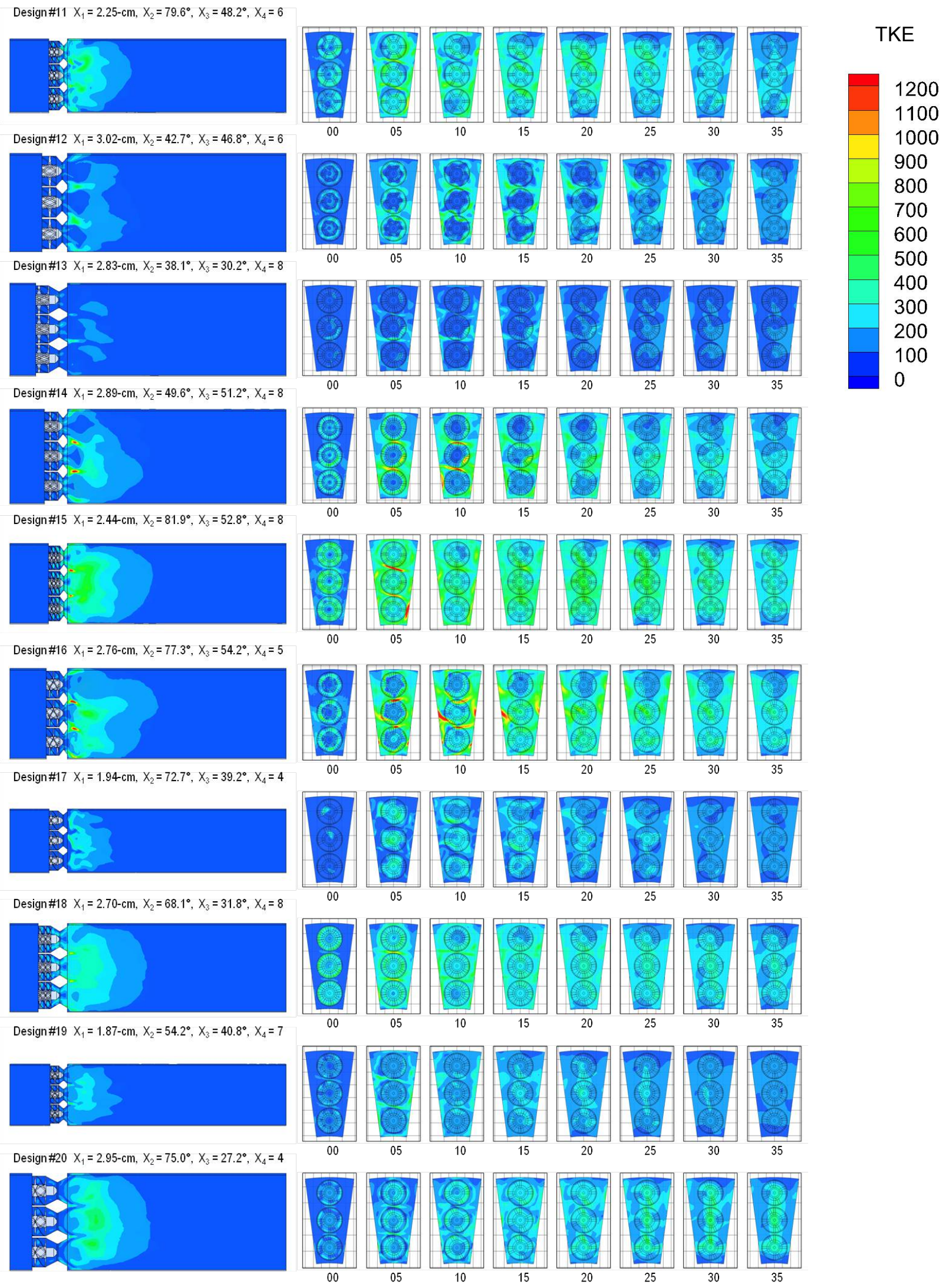

Figure 21. Turbulent kinetic energy contours for configurations 11 through 20. 


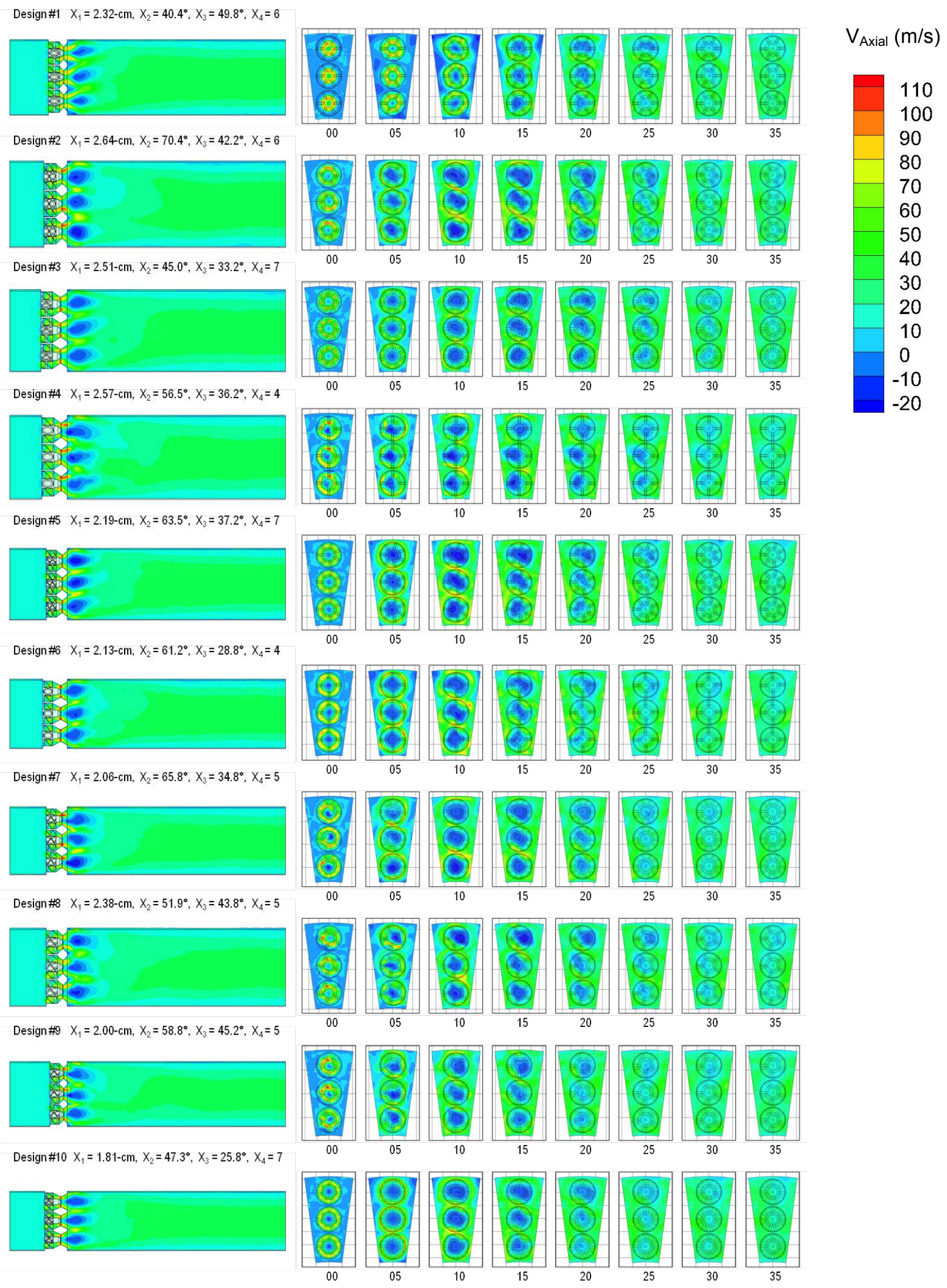

Figure 22. Axial velocity contours for configurations 1 through 10. 


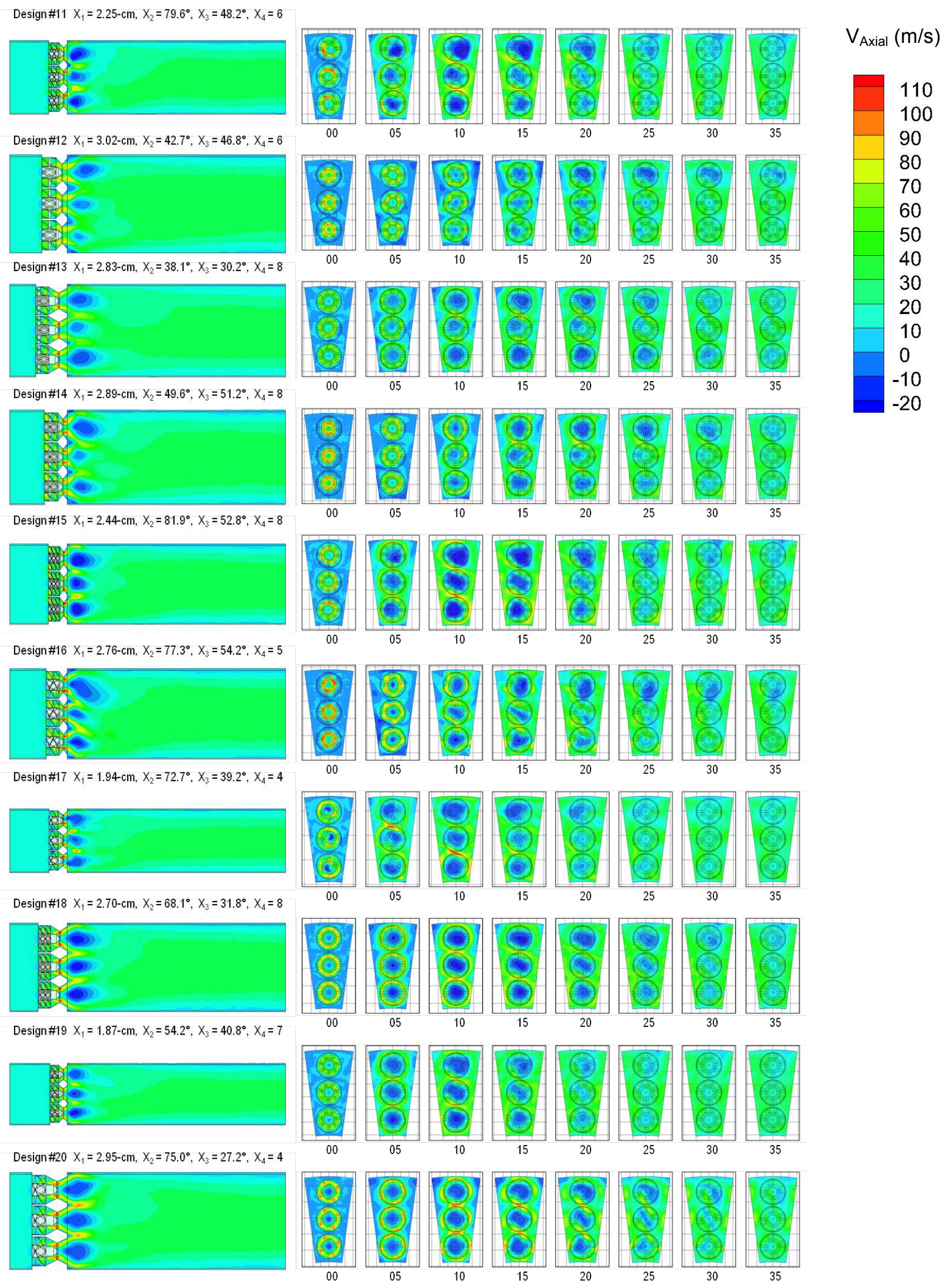

Figure 23. Axial velocity contours for configurations 11 through 20. 


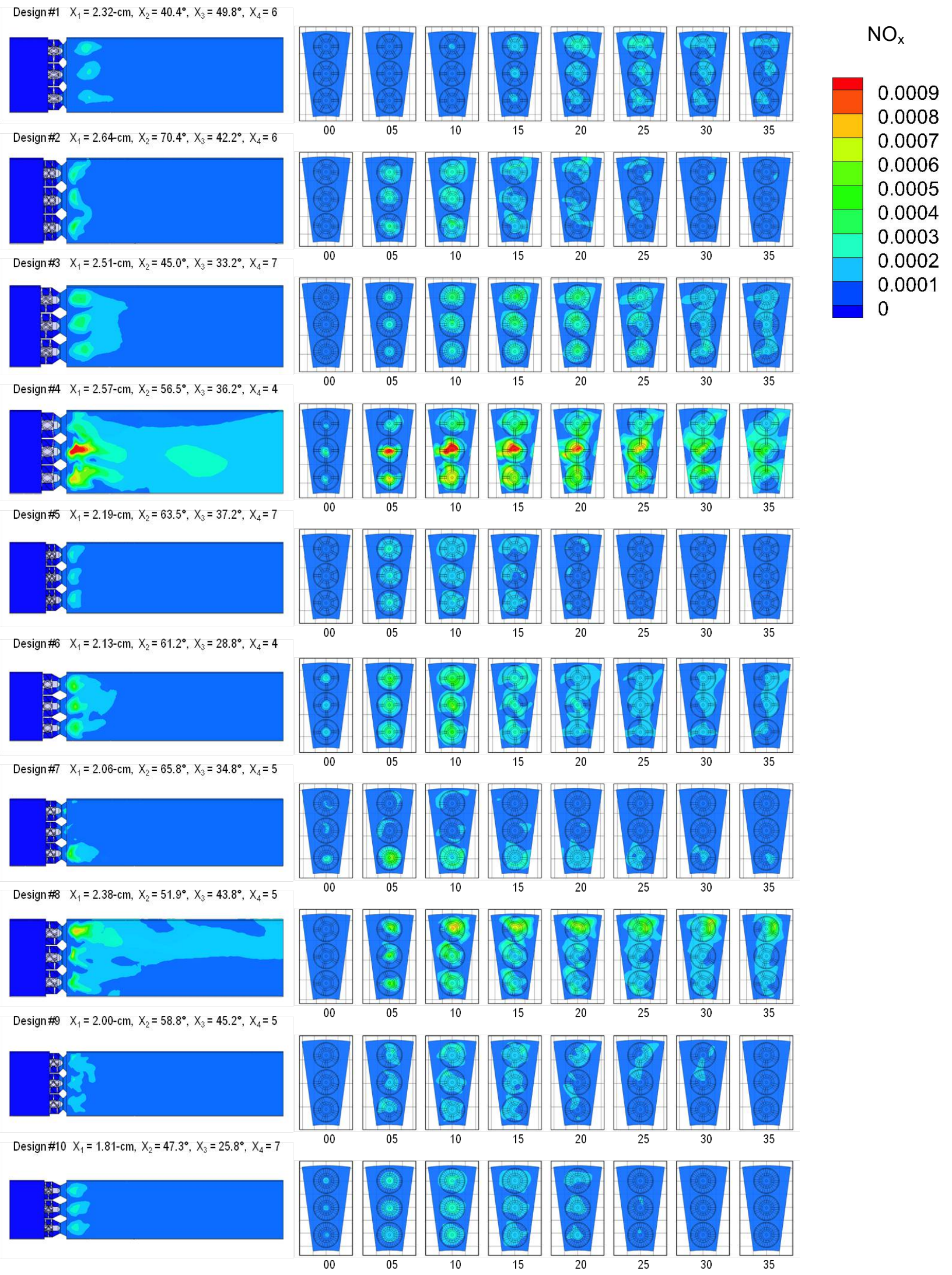

Figure 24. $\mathrm{NO}_{\mathrm{x}}$ (mass fraction) contours for configurations 1 through 10. 


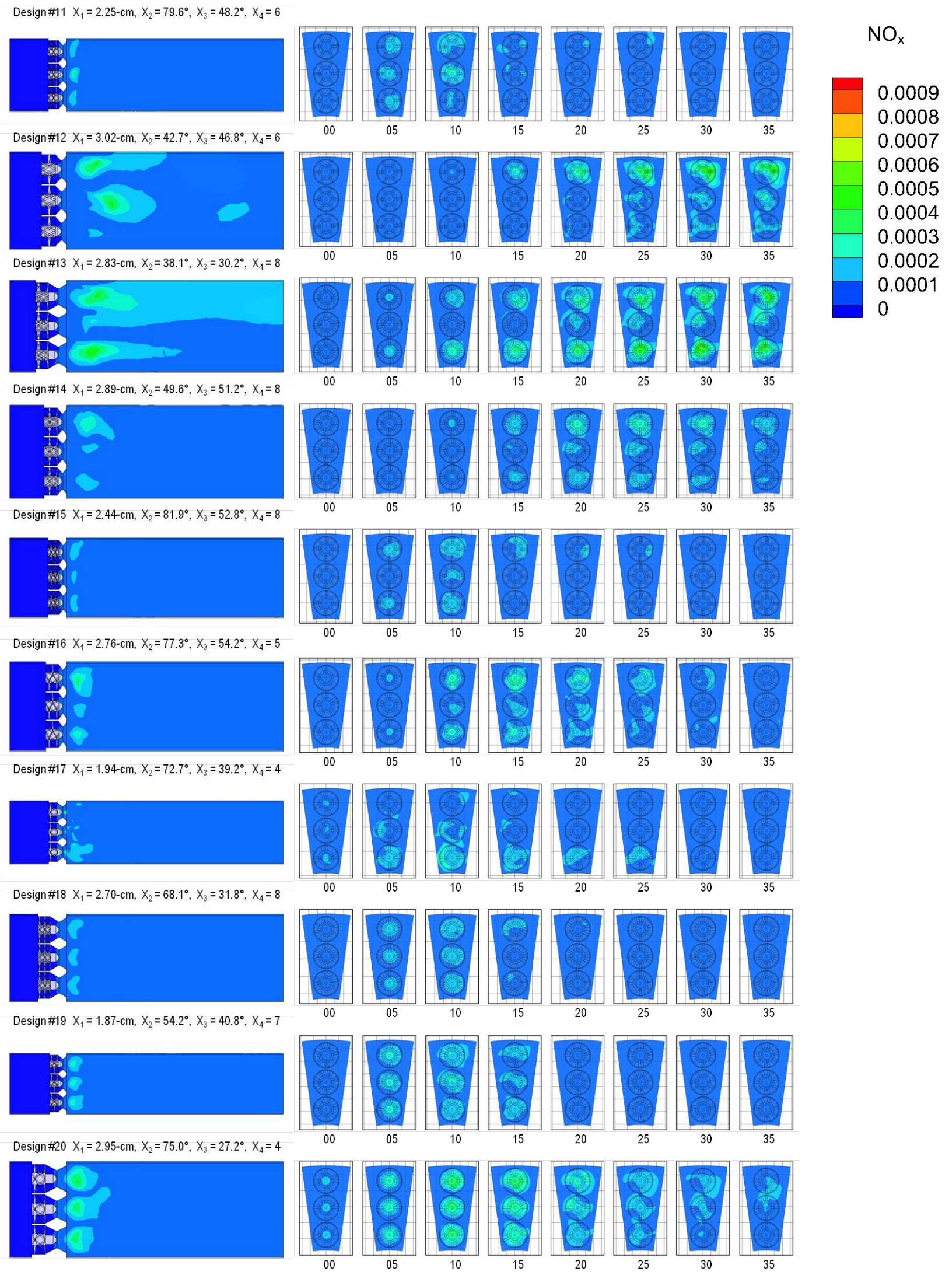

Figure 25. $\mathrm{NO}_{\mathrm{x}}$ (mass fraction) contours for configurations 11 through 20. 


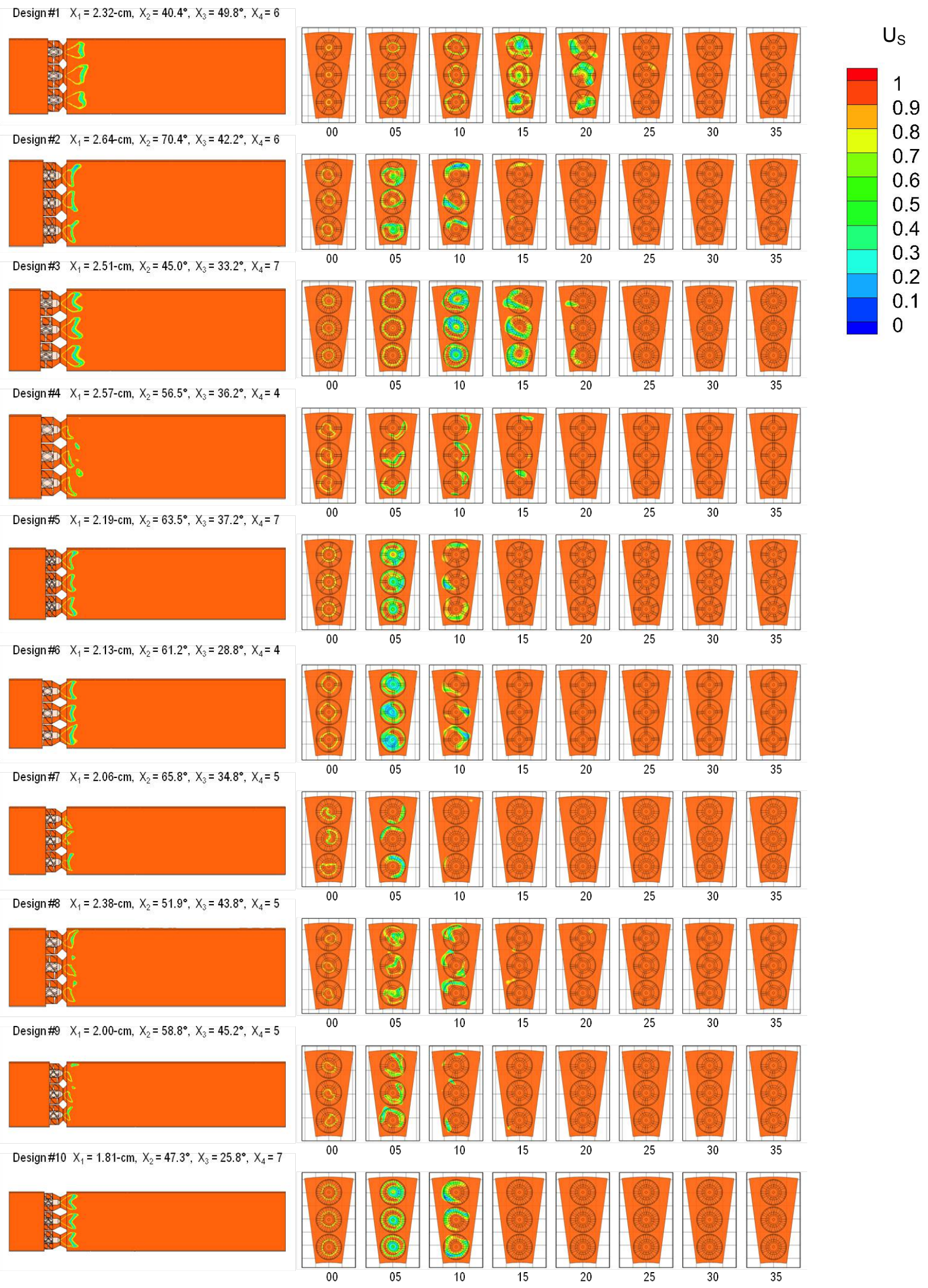

Figure 26. Unmixedness contours for configurations 1 through 10. 


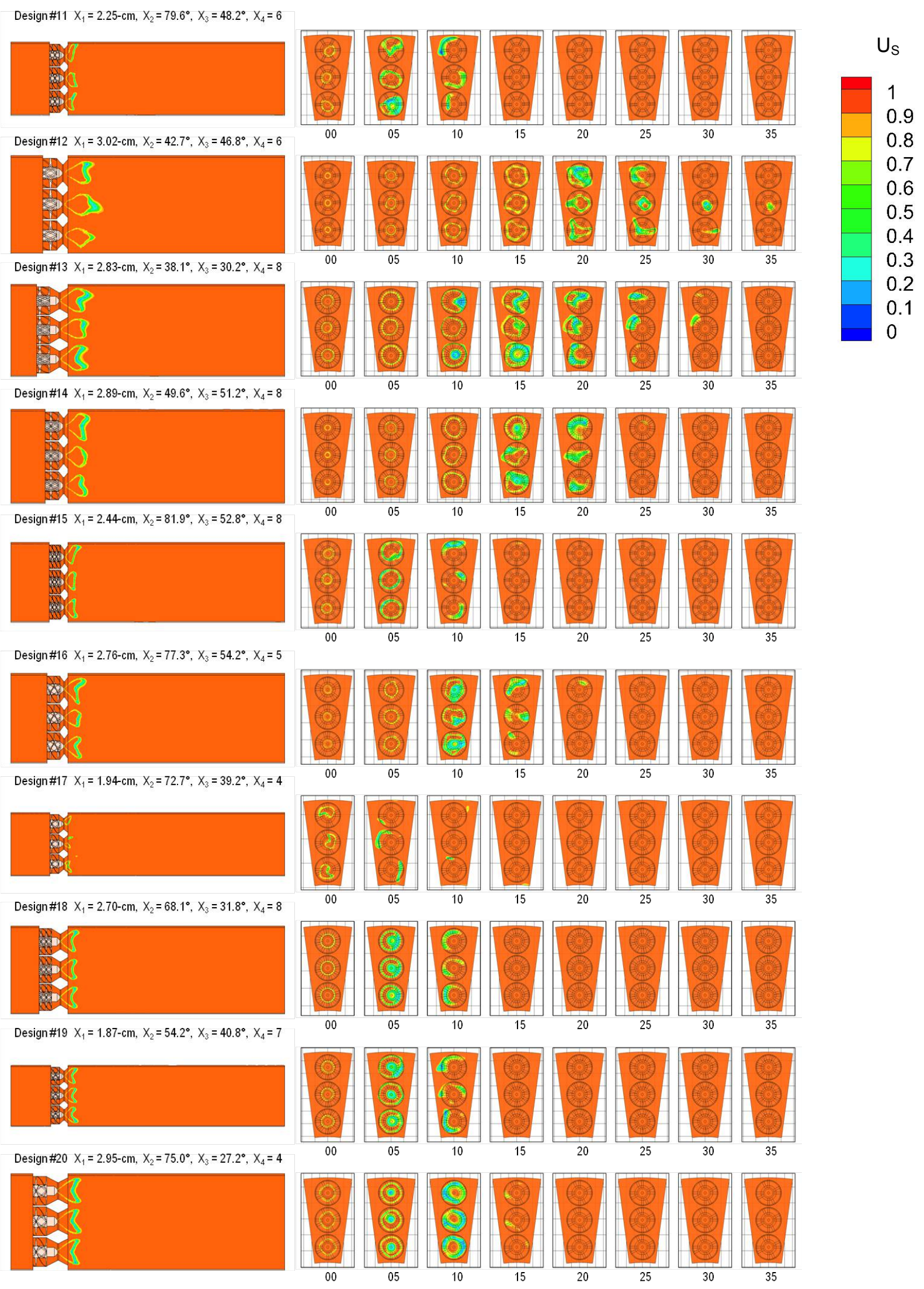

Figure 27. Unmixedness contours for configurations 11 through 20. 
Design\#1 $X_{1}=2.32-\mathrm{cm}, X_{2}=40.4^{\circ}, X_{3}=49.8^{\circ}, X_{4}=6$

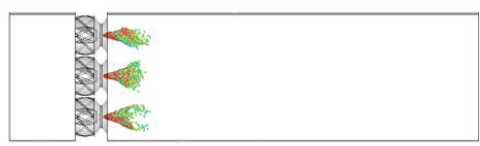

Design $\# 2 \quad X_{1}=2.64-\mathrm{cm}, X_{2}=70.4^{\circ}, X_{3}=42.2^{\circ}, X_{4}=6$

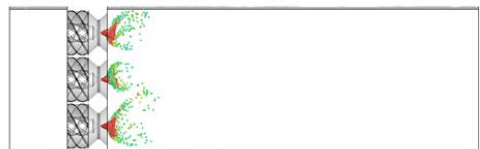

Design \#3 $X_{1}=2.51-\mathrm{cm}, X_{2}=45.0^{\circ}, X_{3}=33.2^{\circ}, X_{4}=7$

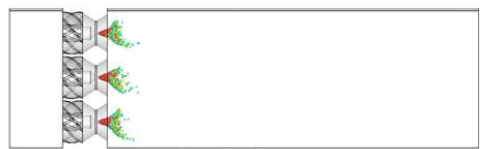

Design\#4 $X_{1}=2.57-\mathrm{cm}, X_{2}=56.5^{\circ}, X_{3}=36.2^{\circ}, X_{4}=4$

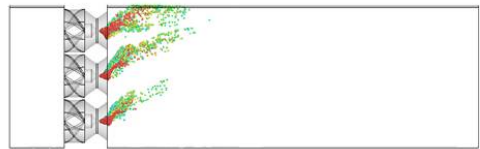

Design\#5 $X_{1}=2.19-\mathrm{cm}, X_{2}=63.5^{\circ}, X_{3}=37.2^{\circ}, X_{4}=7$

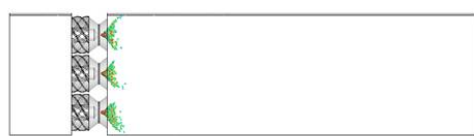

Design \#6 $X_{1}=2.13-\mathrm{cm}, X_{2}=61.2^{\circ}, X_{3}=28.8^{\circ}, X_{4}=4$

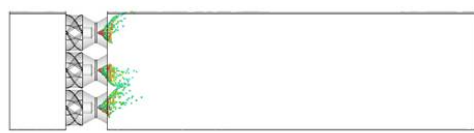

Design\#7 $X_{1}=2.06-\mathrm{cm}, X_{2}=65.8^{\circ}, X_{3}=34.8^{\circ}, X_{4}=5$

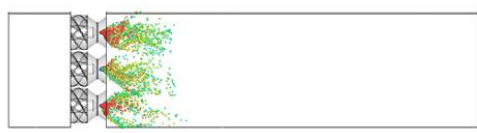

Design \#8 $X_{1}=2.38-\mathrm{cm}, X_{2}=51.9^{\circ}, X_{3}=43.8^{\circ}, X_{4}=5$

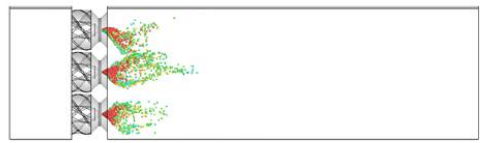

Design \#9 $X_{1}=2.00-\mathrm{cm}, X_{2}=58.8^{\circ}, X_{3}=45.2^{\circ}, X_{4}=5$

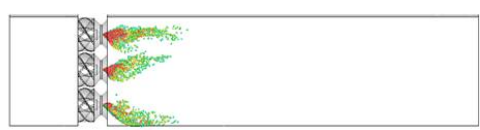

Design \#10 $X_{1}=1.81-\mathrm{cm}, X_{2}=47.3^{\circ}, X_{3}=25.8^{\circ}, X_{4}=7$

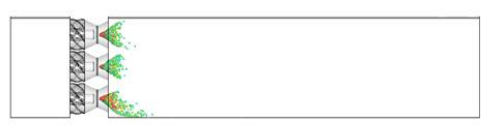

Design\#11 $X_{1}=2.25-\mathrm{cm}, X_{2}=79.6^{\circ}, X_{3}=48.2^{\circ}, X_{4}=6$

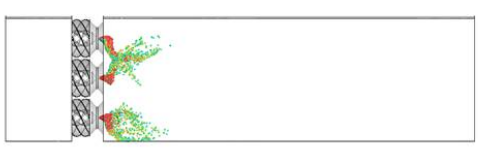

Design\#12 $X_{1}=3.02-\mathrm{cm}, X_{2}=42.7^{\circ}, X_{3}=46.8^{\circ}, X_{4}=6$

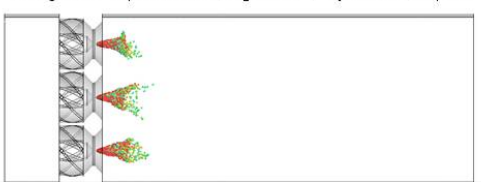

Design\#13 $X_{1}=2.83-\mathrm{cm}, X_{2}=38.1^{\circ}, X_{3}=30.2^{\circ}, X_{4}=8$

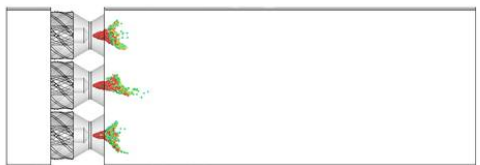

Design\#14 $X_{1}=2.89-\mathrm{cm}, X_{2}=49.6^{\circ}, X_{3}=51.2^{\circ}, X_{4}=8$

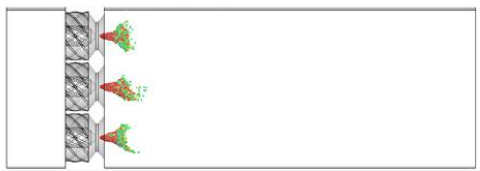

Design\#15 $X_{1}=2.44-\mathrm{cm}, X_{2}=81.9^{\circ}, X_{3}=52.8^{\circ}, X_{4}=8$

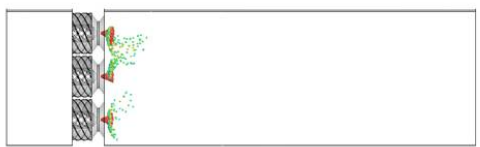

Design\#16 $X_{1}=2.76-\mathrm{cm}, X_{2}=77.3^{\circ}, X_{3}=54.2^{\circ}, X_{4}=5$

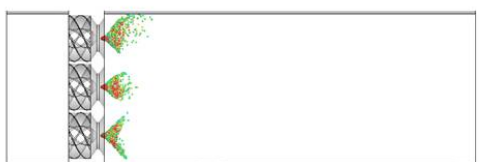

Design\#17 $X_{1}=1.94-\mathrm{cm}, X_{2}=72.7^{\circ}, X_{3}=39.2^{\circ}, X_{4}=4$

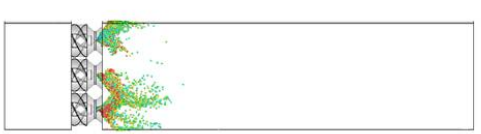

Design \#18 $X_{1}=2.70-\mathrm{cm}, X_{2}=68.1^{\circ}, X_{3}=31.8^{\circ}, X_{4}=8$

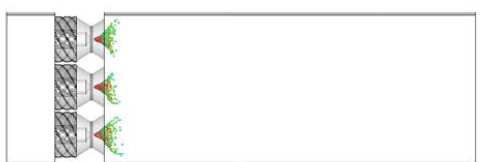

Design\#19 $X_{1}=1.87-\mathrm{cm}, X_{2}=54.2^{\circ}, X_{3}=40.8^{\circ}, X_{4}=7$

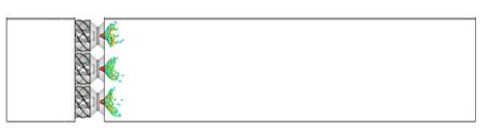

Design $\# 20 \quad X_{1}=2.95-\mathrm{cm}, X_{2}=75.0^{\circ}, X_{3}=27.2^{\circ}, X_{4}=4$

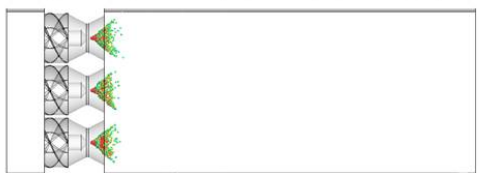

Diameter $(\mu \mathrm{m})$

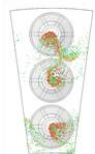

50

45

40

35

30

25

20

15

10

5

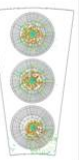

Figure 28. Reacting liquid spray patterns for configurations 1 through 20. 


\section{Acknowledgments}

The author gratefully acknowledges the support of the Supersonics and Fixed Wing Projects of the NASA Fundamental Aeronautics Program. Also, a special thanks to Jonathan Seidel for providing the inspiration for this research, Jeffrey Moder for the numerous enhancements made to the National Combustion Code, and the NASA OpenMDAO development team, especially Justin Gray, for providing software integration assistance.

\section{References}

${ }^{1}$ U.S. Government Accountability Office. Report to Congressional Committees. "Aviation and Climate Change: Aircraft Emissions Expected to Grow, but Technological and Operations Improvements and Government Policies Can Help Control Emissions", GAO-09-554, 2009.

${ }^{2}$ Tacina, R., Lee, P., and Wey, C., “A Lean-Direct-Injection Combustor Using a 9 Point Swirl-Venturi Fuel Injector", ISABE-2005-1106, 2005.

${ }^{3}$ Tacina, R., Wey, C, Laing, P., and Mansour, A., 2002, "Sector Tests of a Low-NOx, Lean Direct Injection, Multipoint Integrated Module Combustor Concept," ASME Paper No. GT-2002-30089.

${ }^{4} \mathrm{Fu}$, Y., "Aerodynamics and Combustion of Axial Swirlers," Ph.D. Dissertation, Department of Aerospace Engineering and Engineering Mechanics, university of Cincinnati, Cincinnati, OH, 2008.

${ }^{5}$ Hicks, Y. R., Heath, C. M., Anderson, R. C. and Tacina, K. M., "Investigations of a Combustor Using a 9-Point Swirl-Venturi Fuel Injector: Recent Experimental Results", ISABE-2011-1106, 2011.

${ }^{6}$ Heath, C., Hicks, Y., Anderson, R., and Locke, R., "Optical Characterization of a Multipoint Lean Direct Injector for Gas Turbine Combustors: Velocity and Fuel Drop Size Measurements," Proceedings of ASME Turbo Expo 2010: Power for Land, Sea and Air GT2010, ASME, GT2010-22960, Glasgow, 2010.

${ }^{7}$ Ajmani, K., Mongia, H., Lee, P., "Evaluation of CFD Best Practices for Combustor Design: Part II - Reacting Flows," AIAA Paper No. 2013-1143, 2013.

${ }^{8}$ Mongia, H. C., 2001, "A Synopsis of Gas Turbine Combustor Design Methodology Evolution of Last 25 Years," Paper No. ISABE-2001-1086.

${ }^{9}$ Mongia, H. C., "Aero-Thermal Design and Analysis of Gas Turbine Combustion Systems: Current Status and Future Direction," AIAA Paper No. 98-3982, 1998.

${ }^{10}$ Duchaine, F., Morel, T., Gicqual, L.Y.M., 2009, “Computational-Fluid-Dynamics-Based Kriging Optimization Tool for Aeronautical Combustion Chambers," AIAA Journal, Vol. 47, Issue 3, 2009, pp. 631-645.

${ }^{11}$ Wankhede, M. J., Bressloff, N. W., Keane, A. J., "Combustor Design Optimization Using Co-Kriging of Steady and Unsteady Turbulent Combustion," Journal of Engineering for Gas Turbines and Power, Vol. 133, Issue 12, 2011.

${ }^{12}$ Rizk, N. K., Mongia, H. C., "Semianalytical Correlations for $\mathrm{NO}_{\mathrm{x}}$, CO, and UHC Emissions," Journal of Engineering for Gas Turbines and Power, Vol. 115, 1993, pp. 612-619.

${ }^{13}$ Rizk, N. K., Mongia, H. C., "A Semi-Analytical Emissions Model for Diffusion Flame, Rich/Lean and Premixed Lean Combustors," Journal of Engineering for Gas Turbines and Power, Vol. 117, 1995, pp. 290-301.

${ }^{14}$ Dewanji, D. G., Rao, A. G., Pourquie M., van Buijtenen, J. P., "Investigation of Flow Characteristics in Lean Direct Injection Combustors," Journal of Propulsion and Power, Vol. 28, No. 1, 2012, pp. 181-196.

${ }^{15}$ Lefebvre, A. H., "Atomization and Sprays," Combustion: An International Series, edited by N. Chigier, Hemisphere Publishing Corporation, Washington D.C., 1989, Chap. 6.

${ }^{16}$ Ajmani, K., Breisacher, K. J., "Computational Modeling of Discrete-Jet Lean Direct Injectors," $48^{\text {th }}$ AIAA/ASME/SAE/ASEE Joint Propulsion Conference and Exhibit, July 30-Aug. 1, 2012, Atlanta, GA.

${ }^{17}$ NASA, "NPSS User Guide: Rev. 1.6.5”, Mar 12, 2008, Cleveland, OH.

${ }^{18}$ Stubbs, R., M., and Liu, N.-S., "Preview of the National Combustion Code", AIAA Paper 1997-3114, 33rd AIAA/ASME/SAE/ASEE Joint Propulsion Conference and Exhibit, July 6-9, 1997, Seattle, WA.

${ }^{19}$ Chen, K.-H., Norris, A. T., Quealy, A., and Liu, N.-S., "Benchmark Test Cases for The National Combustion Code", AIAA Paper 1998-3855, 34th AIAA/ASME/SAE/ASEE Joint Propulsion Conference and Exhibit, July 1315, 1998, Cleveland, OH.

${ }^{20}$ Shih, T.-H., Chen, K.-H., and Liu, N.-S., “A Non-Linear k-epsilon Model for Turbulent Shear Flows,” AIAA Paper 1998-3983, 1998.

${ }^{21}$ Iannetti, A. C., Liu, N.-S., Davoudzadeh, F. "The Effect of Spray Initial Conditions on Heat Release and Emissions in LDI CFD Calculations", NASA-TM-2008-215422, Oct. 2008, Cleveland, OH.

${ }^{22}$ Iannetti, A. C., Moder, J. P., "Comparing Spray Characteristics from Reynolds Averaged Navier-Stokes (RANS) National Combustion Code (NCC) Calculations Against Experimental Data for a Turbulent Reacting Flow,” NASA-TM-2010-216735, July 2010, Cleveland, OH. 
${ }^{23}$ Chen, K. -H., Liu, N. -S., "Evaluation of a Nonlinear Turbulence Model Using Mixed Volume Unstructured Grids," AIAA Paper No. 98-0233.

${ }^{24}$ Raju, M. S., "LSPRAY-IV: A Lagrangian Spray Module", NASA-CR-2012-217294, Feb. 2012, Cleveland, $\mathrm{OH}$.

${ }^{25}$ Zeldovich, Y. B., "The Oxidation of Nitrogen in Combustion and Explosions," Acta Physicochimica, URSS 2, pp. 577-628, 1946.

${ }^{26}$ Fennimore, C.P., 13th Symposium. (Int) Comb., 1971, p.371.

${ }^{27}$ OpenMDAO.org, Gray, Justin S., 2011, NASA, Nov 21, 2011, <http://openmdao.org/ > .

${ }^{28}$ Liscinsky, D. S., True, B., Holdeman, J. D., "Effects of Inlet Flow Conditions on Crossflow Jet Mixing," 32 ${ }^{\text {nd }}$ AIAA/ASME/SAE/ASEE Joint Propulsion Conference and Exhibit, July 1-3, 1996, Lake Buena Vista, FL. 